\title{
Application of NSGA-II and Improved Risk Decision Method for Integrated Water Resources Management of Malian River Basin
}

\author{
Yayu Gao ${ }^{1,2,3, *}$, Xinmin Zhang ${ }^{4}$, Xiaoyou Zhang ${ }^{1,2}$, Duan $\mathrm{Li}^{1,2}$, Min Yang ${ }^{2,5}$ and Jinhua Tian ${ }^{3}$ \\ 1 Key Laboratory of Eco-hydrology of Inland River Basin, Northwest Institute of Eco-Environment and \\ Resources, Chinese Academy of Sciences, Lanzhou 730000, China \\ 2 Chinese Academy of Sciences, Beijing 100049, China \\ 3 Gansu Provincial Soil and Water Conservation Research Institute, Lanzhou 730000, China \\ 4 Gansu Provincial Water Science Research Institute, Lanzhou 730000, China \\ 5 State Key Laboratory of Cryospheric Science, Northwest Institute of Eco-Environment and Resources, \\ Chinese Academy of Sciences, Lanzhou 730000, China \\ * Correspondence: gaoyayu18@mails.ucas.ac.cn
}

Received: 5 July 2019; Accepted: 7 August 2019; Published: 9 August 2019

\begin{abstract}
The Malian River Basin is the Longdong grain elevator and a new oil and energy base of East Gansu Province. Limited water resources programming utilization is a key for the development of the socio-economic and energy industry, as well as the improvement of the ecological environment. An analytical framework for assessing socioeconomic development, rational allocation of water resources, and guiding policy development is proposed in this study. A decision tree method was used in the risk analysis and was improved by introducing the expert advisory probabilistic method into the sensitivity analysis to reduce cognitive bias. A large-system multi-objective model was developed to solve the problem of the rational allocation of available water resources and for benefit maximization among water users. The Non-dominated Sorting Genetic Algorithm-II (NSGA-II) method was used to generate a solution. The water supply amount within the basin was $8.69 \times 10^{8} \mathrm{~m}^{3}$ and the water shortage rate was $15.90 \%$. The optimization model method had better distribution results than the weights method without new water supply. Through the model method results, the water saving potential was found and the related policies were proposed. The framework and methods can further provide a reference for both the planning of water resources and the formulation of regulatory policies and will greatly alleviate water crises in semi-arid areas.
\end{abstract}

Keywords: integrated management of water resources; large-system multi-objective model; NSGA-II method; risk decision-making; improved decision tree method; Malian River Basin

\section{Introduction}

Located in a semi-arid region, the Malian River Basin (Figure 1), situated at the Loess gully area at the upper Jin river of Yellow River, is a traditional agricultural region, called the Longdong grain elevator. It has great development potential because of its rich resources, such as oil, coal, and gas. As such, it is a new oil and energy base of East Gansu Province. Although annul precipitation reaches up 450-500 $\mathrm{mm}$, the average water resources in the Malian River Basin are only 449 million $\mathrm{m}^{3}$, based on the data for a number of years. The per capita consumption is $352 \mathrm{~m}^{3} / \mathrm{a}$, accounting for $25.7 \%$ of the per capita consumption of Gansu Province, China. The flood runoff in the two months, July and August, accounts for more than $50 \%$ of the annual runoff volume. The volume of runoff during the remaining ten months of the year accounts for only $40 \%$ of the annual runoff volume. Hence, there were many water resource problems in the basin, such as low total runoff volume, uneven 
runoff distribution between seasons and years, scarce conventional water resources, and worsening water pollution. Most important, the existing amount of water resources cannot support the rapid socio-economic development of the basin. In the basin, almost all the research is about controlling water pollution, simulating runoff, and water chemical analysis [1-6]. However, how to allocate the precious water, how to support the rapid development of the social economy, and how to adjust the policy to adapt rapid social development changes are not studied.

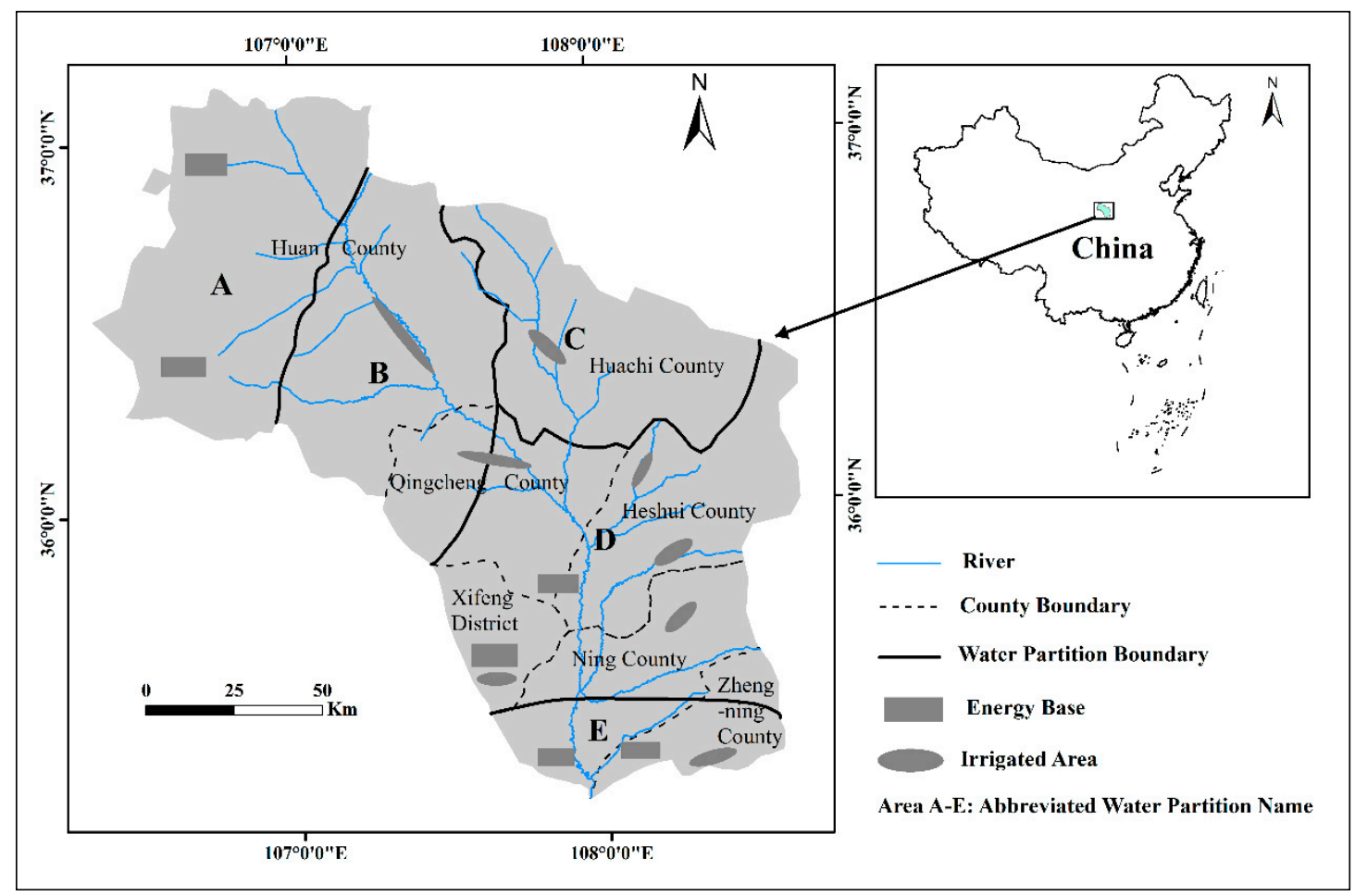

Figure 1. Water resource partitions and locations in Malian River Basin (Pastoral Energy Industry Partition, Farming-Pastoral Industrial Development Partition, Ecological Agriculture Preserved Partition, Sustainable Development for Petroleum and Coal Industry Partition, and Preserved Partition for Ecological Agriculture and Sustainable Coal Industry Development Partition were abbreviated as A-E in the figure).

In the allocation of water resources, due to its scarcity, it is impossible to satisfy the water demand of every user at the same time. To provide reliable and sustainable water resources for the rapid transition from traditional agricultural to new energy industrial, it is very necessary to allocate and use the water resources more rationally. Thus, to make full use of the limited water resources and to minimize the risk of water shortages, the theory of risk decision analysis in economics and the large-scale multi-objective model were introduced. In terms of risk decision, Zhang (1983) et al. were the first to apply the fuzzy set theory to risk decision [7]. Subsequent research basically used model results to support decision/policy-making, optimize the allocation of water resources, and efficiently collect and utilize water resources [8-19]. In terms of the large-scale multi-objective model and the Non-dominated Sorting Genetic Algorithm-II (NSGA-II) method, most of the research is focused on water resource management [20-34]. Unfortunately, nearly all the risk decision analyses on water resource systems have primarily focused on flood control systems and reservoir operation [35]. The risk decision on water resources allocation has rarely been reported.

The authors have applied a decision tree method to risk decision in water resource allocation for the first time, based on the theory of risk decision in economics. They have also introduced the results of an expert advisory probability method into the sensitivity analysis in order to reduce the bias of expert consultation. Meanwhile, a large systematic multi-objective model for optimal water 
resource allocation was constructed using systematic analysis theory and optimization techniques. The NSGA-II method was used to generate solutions. The optimal results can effectively eliminate deviation from any inaccurate forecast and achieve maximum comprehensive benefits for different partitions and users. In semi-arid areas, it is of great significance to carry out the research, such as how to provide strong water resource insurance to the fast-growing social economy and the new energy industry, and the optimal allocation of limited water resources to different users. The methods can further provide a reference for both the planning of water resources and the formulation of regulatory policies and will greatly alleviate water crises in semi-arid areas.

\section{Study Area}

The Malian River Basin is located in the deep inland region of complicated terrain. Its total length is $374.8 \mathrm{~km}$ and the total area is $19,086 \mathrm{~km}^{2}$. It is situated at middle latitude and has a temperate continental climate. The basin is spread among seven counties (districts) of Qingyang, including Huan County, Huachi County, Qingcheng County, Heshui County, Ning County, Zhengning County, and Xifeng District (Figure 1). The total population within the basin is 2.02 million, of which 1.3617 million are an agricultural population and 0.6593 million are non-agricultural. The agricultural structure within the basin mainly consists of farming and animal feeding. Winter wheat is the main crop, accounting for $60 \%$ to $70 \%$ of the total planting area, which is distributed to every county (district). There are abundant coal, oil, and natural gas reserves in the basin. The rapid transition from traditional agricultural production areas to new energy industrial areas makes Malian River Basin facing new and huge challenges. And the problem of rapid and sustainable development of the economy with the sustainable use of water resources urgently needs to be solved. Therefore, the selection of the Malian River Basin as a research area had better representativeness and typicality in semi-arid region.

\section{Methods}

The optimal allocation of water resources in the Malian River Basin is a large complex system involving water, society, the economy, and the ecological environment. In order to make water resources better adapt to the rapid development of economy, and the goals of resources, environment, society, and economy should be achieved. Therefore, a large-scale multi-objective water resource optimal allocation model was established, which used decomposition-coordination techniques to optimize the solution process of the entire model. Simultaneously, in order to reduce the bias of expert consultation results, the decision tree method was introduced and the recommended program of the decision tree method was put into the large-system and multi-objective model. Then, optimal allocation of water resources in the basin was implemented between different water users in different water resource divisions. Finally, the model operation results and the supply and demand balance analysis results were compared and analyzed. According to the comparison results, the development speed of the social economy and water conservancy projects was adjusted and the guidance for policy formulation was provided (Research steps and framework are shown in Figure 2.). 


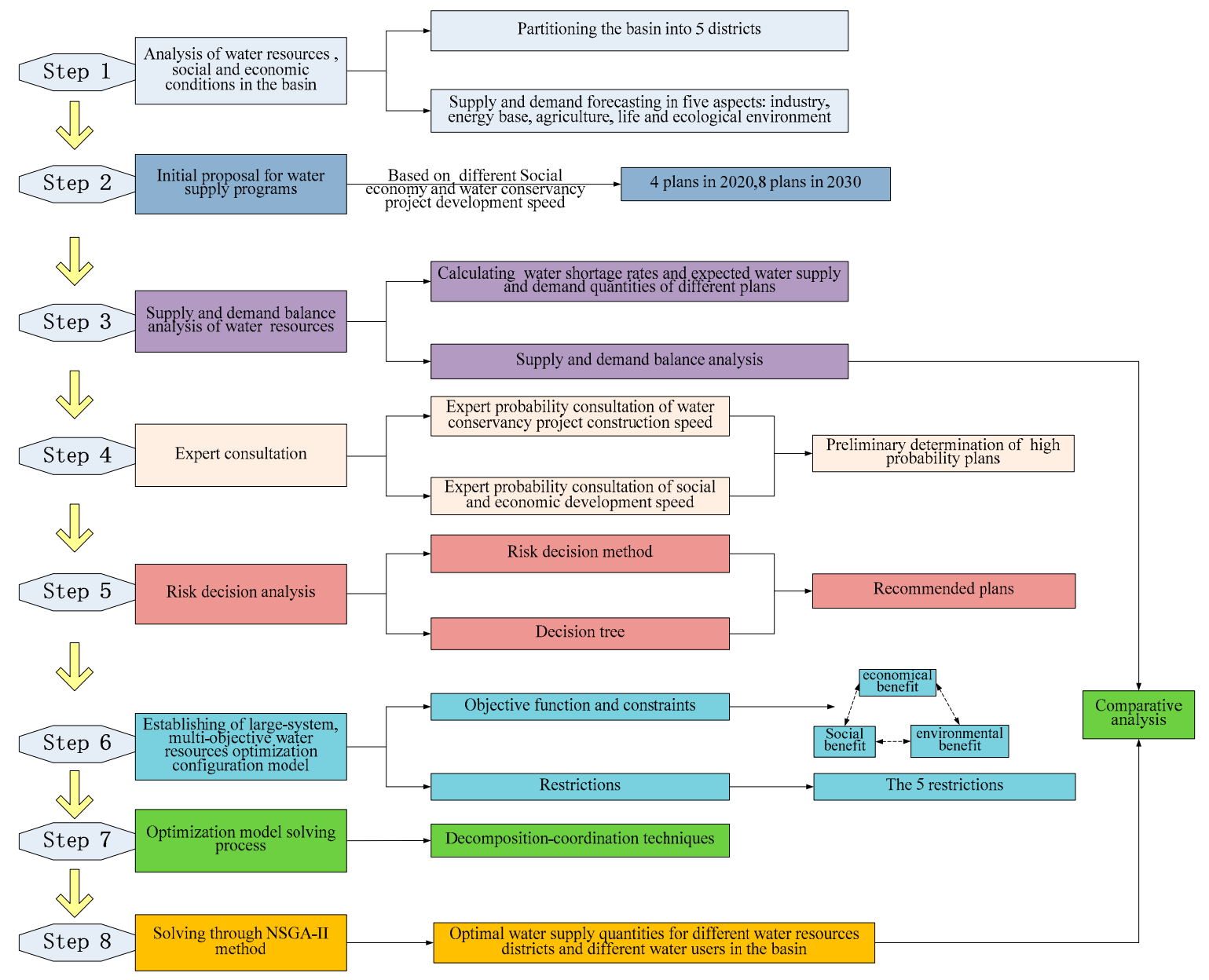

Figure 2. Research steps and framework.

\subsection{Data Collection}

The analytical data was purchased from the Gansu Provincial Meteorological Bureau, the Water Affairs Bureau of Qingyang City, and the Statistics Affairs Bureau of Qingyang City. Analysis of the construction of social economy and water conservancy projects was based on "The 13th Five-Year Plan" Comprehensive Planning of Qingyang City, "The 13th Five-Year Plan of Water Conservancy" of Qingyang City, the and Medium and Long-term Water Conservancy Development Plan. The development of different water supply and demand programs were based on the Water Resources Guarantee Plan of Energy Base Construction of Qingyang City, the Thematic Analysis of Long-term Water Demand Forecasting, the Water Supply Capacity Analysis of Qingyang City, the Energy Base Comprehensive Plan of Qingyang City, and the Water Saving Society Construction Plan of Qingyang City. (In China "The 13th Five-Year" represents 2016 to 2020.)

\subsection{The Risk Decision Analysis and Expert Advisory Probabilistic Method}

\subsubsection{Methods Introduction}

A risk decision means a decision made under an uncertain state and some uncontrollable factors may lead to different results at different probabilities. The expert advisory probabilistic method started with consulting the relevant experts anonymously. After calculating the statistics, processing, analyzing, and concluding the experts' opinions, the most comprehensive expertise and subjective judgments were summarized. This method is able to give reasonable estimates on many factors that are difficult to analyze quantitatively using other technical methods. After several rounds of consultation, feedback, and adjustments, based on the final analysis, the conclusion was drawn. 
The probability of expert consultation in the Malian River Basin should first predict the speed of social and economic development, the water demand, and the provided water availability. Then, a probabilistic consultation on the prediction results to get the probability of different programs should be conducted. Finally, expert recommendation programs can be obtained. Different socio-economic development speeds will result in different water quotas to determine the water demand at different development speeds. Therefore, the development problems within the basin can be translated into the problem of determining and allocating water demand and supply.

(1) Social and economic development speed forecast

The prediction of social and economic development was divided into high-speed and low-speed development, and the socio-economic growth indicators of different development speeds was predicted, as shown in Table 1.

Table 1. Forecast of social and economic development speed in different planning levels. Population growth rate (PGR, \%), urbanization rate (UR, \%), coal mine $\left(\mathrm{CM}, 10^{4}\right.$ ton), petrochemical (PC, $10^{8}$ ton), power plant $\left(\mathrm{PP}, 10^{4} \mathrm{KW}\right)$, industrial increased $\left(\mathrm{I}_{\mathrm{i}}, \%\right)$, tertiary industry increased (TII, \%), ecological area increased (EAI, \%), and irrigation area increased (IAI, \%), were selected to measure the development of social economy.

\begin{tabular}{ccccccccccc}
\hline Development Speed & Year & PGR & UR & CM & PC & PP & I $_{\mathbf{i}}$ & TII & EAI & IAI \\
\hline \multirow{2}{*}{ Low } & 2020 & 3 & 34 & 8588 & 1015 & 2520 & 13.5 & 11 & 3 & 0.3 \\
& 2030 & 3 & 44 & 9160 & 1538 & 2688 & 12 & 10 & 2 & 0.9 \\
\hline \multirow{2}{*}{ High } & 2020 & 3 & 44 & 11,450 & 1353 & 3360 & 16 & 13 & 3 & 0.6 \\
& 2030 & 3 & 54 & 11,450 & 1923 & 3360 & 14 & 12 & 2 & 1.2 \\
\hline
\end{tabular}

(2) Water demand forecast

Through the prediction of the water quota for different development speeds and the number of water users, the water demand forecast could be completed. The quota forecast is shown in Table 2.

Table 2. Water quota forecast in 2020 and 2030. Rural green space (RGS, $\left.\mathrm{L} / \mathrm{m}^{2}\right)$, urban green space (UGS, $\mathrm{L} / \mathrm{m}^{2}$ ), artificial plantation irrigation (API, $\mathrm{m}^{3} / \mathrm{ha}$ ), urban roads area (URA, $\mathrm{L} / \mathrm{m}^{2}$ ), farmland irrigation (FI, $\mathrm{m}^{3} /$ ha), urban population (UP, L/person-day), rural population (RP, L/person-day), industry (Indus, $\mathrm{m}^{3} / 10^{4}$ yuan added value), construction industry ( $\mathrm{CI}, \mathrm{m}^{3} / 10^{4}$ yuan added value), tertiary industry (TI, $\mathrm{m}^{3} / 10^{4}$ yuan added value), livestock (Liv, L/day), coal mine comprehensive (CMC, $\mathrm{m}^{3} / \mathrm{t}$ ), petrochemical water demand $\left(\mathrm{PWD}, \mathrm{m}^{3} / \mathrm{t}\right)$, and water demand of thermal power and coal gangue power plant (WDT, $\mathrm{m}^{3} / \mathrm{s} \cdot \mathrm{GW}$ ) were selected as the basis for predicting water demand.

\begin{tabular}{ccccccccc}
\hline Contents & $\mathbf{2 0 2 0}$ & $\mathbf{2 0 3 0}$ & Contents & $\mathbf{2 0 2 0}$ & $\mathbf{2 0 3 0}$ & Contents & $\mathbf{2 0 2 0}$ & $\mathbf{2 0 3 0}$ \\
\hline RGS & 90 & 90 & UP & 157 & 160 & Liv & 45 & 45 \\
UGS & 90 & 90 & RP & 116 & 136 & CMC & 0.30 & 0.25 \\
API & 3000 & 3000 & Indus & 30 & 25 & PWD & 0.57 & 0.55 \\
URA & 75 & 75 & CI & 9.5 & 9.5 & WDT & 0.18 & 0.16 \\
FI & 4290 & 3630 & TI & 16 & 16 & & & \\
\hline
\end{tabular}

(3) Water supply forecast

The amount of supplied water mainly depends on the amount of water that can be given by the water conservancy project inside the basin. The determination of the amount of water supply can be divided into high-speed and low-speed development of water conservancy projects. Due to space limitations, only the water conservancy projects in 2030 were listed, and social development in 2020 and2030, the situation in 2020 were omitted. As shown in Table 3, the water conservancy project can increase the water supply capacity by $5.78 \times 10^{8} \mathrm{~m}^{3}$ in high speed development and $3.65 \times 10^{8} \mathrm{~m}^{3}$ in low speed development in 2030. 
Table 3. Water supply forecast table in 2030. The water supple capacity (WPC, $10^{8} \mathrm{~m}^{3}$ ) in the table refers to increased water supply capacity.

\begin{tabular}{|c|c|c|c|}
\hline \multicolumn{2}{|l|}{ High Speed } & \multicolumn{2}{|l|}{ Low Speed } \\
\hline Water Project & WPC & Water Project & WPC \\
\hline Si Lang River Water Diversion Pivot Project $* * *$ & 0.06 & Si Lang River Water Diversion Pivot Project $* * *$ & 0.06 \\
\hline Xiao Pan River Reservoir *** & 0.30 & Xiao Pan River Reservoir *** & 0.30 \\
\hline Xiao Pan River Water Diversion Project $* * *$ & 0.20 & Xiao Pan River Water Diversion Project $* * *$ & 0.20 \\
\hline $\begin{array}{l}\text { Water Storage Project with the Use of Yellow River in } \\
\text { Huan Country }\end{array}$ & 0.25 & $\begin{array}{l}\text { Water Storage Project with the Use of Yellow River in } \\
\text { Huan Country }\end{array}$ & 0.25 \\
\hline Jin River Water Transfer Project *** & 0.30 & Jin River Water Transfer Project *** & 0.30 \\
\hline Wuri Tiangou Diversion Pivot Project $* * *$ & 0.03 & Wuri Tiangou Diversion Pivot Project $* * *$ & 0.03 \\
\hline Zhi Dang River Water Supply Project *** & 0.05 & Zhi Dang River Water Supply Project *** & 0.05 \\
\hline Sum & 1.14 & Sum & 1.14 \\
\hline San Li Qiao Reservoir ** & 0.20 & San Li Qiao Reservoir * & 0.20 \\
\hline $\begin{array}{c}\text { Water quality renovation project in the upper reaches } \\
\text { of Malian River }\end{array}$ & 0.17 & $\begin{array}{c}\text { Water quality renovation project in the upper reaches } \\
\text { of Malian River* }\end{array}$ & 0.17 \\
\hline Er Jiangchuang Water Diversion Project $* *$ & 0.04 & Er Jiangchuang Water Diversion Project * & 0.04 \\
\hline Malian River Reservoir ** & 1.70 & Malian River Reservoir * & 1.70 \\
\hline Bailong River Water Transfer Project ** & 2.00 & / & / \\
\hline Sum & 4.11 & Sum & 2.11 \\
\hline Urban Qianchi Baihu Project & 0.04 & City Qianchi Baihu Project & 0.04 \\
\hline Urban Wastewater Treatment and Utilization Project & 0.31 & Urban Wastewater Treatment and Utilization Project & 0.27 \\
\hline Rural Rainwater Harvesting and Utilization Project & 0.13 & Rural Rainwater Harvesting and Utilization Project & 0.12 \\
\hline Sum & 0.49 & Sum & 0.42 \\
\hline Total & 5.78 & Total & 3.65 \\
\hline
\end{tabular}

Note: * Project is the striving established project, ${ }^{* *}$ project is the demonstration project, ${ }^{* * *}$ project is an already established project.

Based on forecasts of water supply and demand, 12 survey programs for the expert advisory probabilistic method were designed. A 30 member expert panel was formed, comprising eight experts from universities and research institutes in the field of water resources, eight experts in the field of local water administrative departments, eight professionals familiar with the water resources, three project group members, and three experts in the field of socio-economic planning. All the programs were made into an expert consultation table with a detailed scoring instruction description on the top of the table. Through consultation meetings and mails, the experts were made to score the expert probability for different socio-economic development speeds and construction speeds of water conservancy projects. Each expert selected rated the probability survey programs. The probabilities of the programs were the statistical results of $80 \%$ of the expert consultation results.

\subsubsection{Methods of Reducing the Bias of Experts Consultation Results}

To reduce the cognitive and motivational bias of expert advisory and also to help policy makers achieve a consensus, the authors designed the expert consultation form. They introduced the results of expert advisory probability into the decision tree method and, finally, obtained the recommended program. Every social economic development indicator and the approval of water conservancy projects had a corresponding probability, so the experts rated the probability based on the cognition of each project. Then, the authors took the probabilities given by $80 \%$ of the experts to obtain the probability of construction for each project and, finally, obtained the probabilities of water conservancy projects through weighted calculation. According to social development process, the trend and development model of future economic was identified. Combined with planning and professional department planning for economic and social development, the staged development goals of economic and social development in various regions were proposed and the main development indicators of economic and social development were predicted. The principle of scoring the probability of social and economic construction is the same. According to the scores given by the experts for the 12 programs, the water supply and demand forecasts, and the balance analysis results, the expected water demand, the water 
supply, and the shortage rate were then calculated by the weighted average method and adopted as the basic parameters of decision tree method.

\subsection{The Improved Decision Tree Method for Risk Decision}

The decision tree method is a systematic approach that can organize and represent the decision points and uncertainty faced by decision-makers. In addition, it has the advantages of direct representation, easy calculation, and so on [36,37]. The building of a decision tree employs the top-down recursive manner, in which each node represents a test on property, each branch represents an output of test, and each leaf (node) represents one or more categories [38]. The decision tree is a relatively common method of machine learning. In general, a decision tree consists of a node, several internal nodes, and several leaf nodes, and each other node corresponds to an attribute test. The sample set contained in each node is divided into sub nodes according to the result of the attribute test and the root node contains the full set of samples. The path from the root node to each leaf node corresponds to a decision test sequence. The purpose of decision tree learning is to produce a generalization ability; that is, to deal with decision trees that have no example ability [39].

The decision tree used in the allocation of water resources includes all the allocation factors of different programs, but excludes adverse programs with high risk. However, it is difficult to select the optimal solution because even after the exclusion, the number of remaining programs is usually still more than two. Thus, further sensitivity analysis is required. The improved decision tree, therefore, includes the assessment scores from experts in the sensitivity analysis. The feasibility of each optimal solution can be determined through the integrated probability and the expected program. This can prevent deviation resulting from an inaccurate forecast of growth rate, thereby substantially increasing the feasibility of the optimal solution. It also excludes water resources programs with low a probability of socio-economic development and, therefore, provides a more rational allocation program for different partitions and users.

\subsection{Large Systematic and Multi-Objective Model for Optimal Water Resource Allocation}

A large systematic multi-objective model for optimal water resource allocation was constructed using systematic analysis theory and optimization techniques. Through substituting the objective functions and constraints, the large-system multi-objective model was developed. The model explores the optimal program within the limits of objective functions and constraints. The ultimate goal of the large-system multi-objective model is to allocate water resources for optimal integrated benefits. There are three objective functions, social benefit, economic benefit, and environmental benefit. The model therefore searches for a program that gives optimal integrated benefits.

\subsubsection{Objective Functions}

The final result of the large-scale water resources system and multi-objective optimization model is that the comprehensive benefits are optimal. There are three objective functions of the model. Social benefits are a difficult target to measure, so only considering the impact of water resources on society. The impact can be considered that the amount of water shortage directly affects the development and stability of society. Therefore, the social benefit objective is reflected indirectly by minimizing the total water shortage in each water resource division. The economic benefit objective is expressed by the direct benefit of water supply reached the maximum and the environmental benefit objective is expressed by the minimum pollutant discharge. The model form is as follows:

$$
\left\{\begin{array}{c}
\operatorname{Max}\left[f_{1}(x), f_{2}(x), f_{3}(x)\right] \\
G(x) \leq 0 \\
x \geq 0
\end{array},\right.
$$


where $x$ is the decision variables, $f_{1}(x)$ is social the benefit function, $f_{2}(x)$ is the economic benefit function, $f_{3}(x)$ is environmental benefit function, $G$ is the function of restrictions set, which indicates equations of water resource carrying capacity, environmental capacity, land resources, other social constraints and subsystem states, etc.

The objective function expressions for social, economic, and environmental benefits are as follows:

Objective 1: The social benefit function is measured by the minimum water shortage in each water resources division, and the expression is as follows:

$$
\min f_{1}(x)=\sum_{k=1}^{k} \sum_{j=1}^{J(k)}\left[D_{j}^{k}-\left(\sum_{i=1}^{J(k)} x_{i j}^{k}+\sum_{c=1}^{M} x_{c j}^{k}\right)\right]
$$

where $D_{j}^{k}$ is user $j^{\prime}$ s water demand quantity in the $k$ sub-district, $x_{i j}^{k}$ and $x_{c j}^{k}$ are the amount of water supplied by the independent water source $i$ and public water source $c$ to user $j$ in the $k$ sub-district (hundred million $\mathrm{m}^{3}$ ).

Objective 2: The economic benefit function is measured by the maximum net benefit of the water supply in each water resource division, and the expression is as follows:

$$
\max f_{2}(x)=\sum_{k=1}^{K} \sum_{j=2}^{J(k)} \sum_{i=1}^{I(k)}\left(b_{i j}^{k}-c_{i j}^{k}\right) x_{i j} \alpha_{i}^{k} \beta_{j}^{k} w_{k}+\sum_{k=1}^{K} \sum_{j=1}^{J(k)} \sum_{c=1}^{M}\left(b_{c j}^{k}-c_{c j}^{k}\right) x_{c j}^{k} \alpha_{c}^{k} \beta_{j}^{k} w_{k},
$$

where $b_{i j}^{k}$ and $b_{c j}^{k}$ are the benefit coefficients of unit water supply amount supplied by independent water source $i$ and public water source $c$ to user $j$ in sub-district $\left(\mathrm{yuan} / \mathrm{m}^{3}\right) k, c_{i j}^{k}$ and $c_{c j}^{k}$ are the cost factor coefficients of unit water supply amount supplied by independent water source $i$ and public water source $c$ to user $j$ in sub-district $k\left(\mathrm{yuan} / \mathrm{m}^{3}\right), \alpha_{1}^{k}$ and $\alpha_{c}^{k}$ are the water supply order coefficients supplied by independent water source $i$ and public water source $c$ to user $j$ in sub-district $k, \beta_{j}^{k}$ is the water fairness coefficient of user $j$ in sub-district $k$, and $w_{k}$ is the weight coefficient in sub-district $k$.

Objective 3: The environmental benefit function is measured by the minimum discharge of important pollutants in the water receiving area, and the expression is as follows:

$$
\min f_{3}(x)=\sum_{K=1}^{K} \sum_{J=1}^{J(k)} p_{J}^{k}\left(\sum_{i=1}^{I(k)} x_{i j}^{k}+\sum_{c=1}^{M} x_{c j}^{k}\right),
$$

where $p_{J}^{k}$ is the sewage discharge coefficient of user $j$ in sub-district $k$.

\subsubsection{Restrictions}

(1) Restrictions of water supply amount

The water supply source generally refers to the public water source, and the expressions are as follows:

$$
\begin{aligned}
& \sum_{j=1}^{J(k)} x_{c j}^{k} \leq D_{c}^{k}, \\
& \sum_{k=1}^{K} D_{c}^{k} \leq W_{c},
\end{aligned}
$$

where $W_{c}$ is water supply amount of public water source $c\left(10^{4} \mathrm{~m}^{3}\right), x_{c j}^{k}$ is water supply amount to user $j$ from public water source $c$ in sub-district $k\left(10^{4} \mathrm{~m}^{3}\right), D_{c}^{k}$ is the amount of water allocated to the sub-district $k$ by the public water source $c\left(10^{4} \mathrm{~m}^{3}\right)$.

(2) Restrictions of water source delivery capacity

$$
\begin{aligned}
& x_{i j}^{k} \leq Q_{i}^{k}, \\
& x_{c j}^{k} \leq Q_{c},
\end{aligned}
$$


where $Q_{i}^{k}$ is the maximum water delivery capacity of water source $i$ in sub-district $k\left(10^{4} \mathrm{~m}^{3}\right)$ and $Q_{c}$ is the maximum water delivery capacity of public water source $c\left(10^{4} \mathrm{~m}^{3}\right)$.

(3) Restrictions of user water delivery capacity

$$
D_{j \min }^{k} \leq \sum_{i=1}^{I(k)} x_{i j}^{k}+\sum_{c=1}^{M} x_{c j}^{k} \leq D_{j \max }^{k}
$$

where $D_{j \min }^{k}$ and $D_{j \max }^{k}$ are the user $j^{\prime}$ 's minimum and maximum water demand in sub-district $k\left(10^{4} \mathrm{~m}^{3}\right)$.

(4) Restrictions of regional coordinated development

$$
u=\sqrt{u_{B_{1}}\left(\delta_{1}\right) u_{B_{2}}\left(\delta_{2}\right)} \geq u^{*},
$$

let $B_{1}$ be a fuzzy subset of water resources utilization and regional economic development, while membership function $u_{B_{1}}\left(\delta_{1}\right)$ indicates coordination degree.

$$
\begin{gathered}
\delta_{1}=\sum_{k=1}^{K} w_{k} \delta_{1}^{k}, \\
\delta_{1}^{k}=\sum_{j=1}^{J(k)} \sum_{i=1}^{I(k)} x_{i j}^{k}+\left(\sum_{c=1}^{M} x_{c j}^{k}\right) / \sum_{j=1}^{J(k)} D_{j}^{k}, \\
u_{B_{1}}\left(\delta_{1}\right)=\left\{\begin{array}{ll}
1.0 & \left(\delta_{1} \geq \delta_{1}^{*}\right) \\
\exp \left(-4\left(\delta_{1}-\delta_{1}^{*}\right)^{2}\right) & \left(\delta_{1}<\delta_{1}^{*}\right)
\end{array},\right.
\end{gathered}
$$

The degree of coordination between economic development and the improvement of water environment quality can be expressed as $u_{B_{2}}\left(\delta_{2}\right)$.

$$
\begin{gathered}
\delta_{2}=\sum_{k=1}^{K} w_{k} \delta_{2}^{k}, \\
\delta_{2}^{k}=\frac{E^{k} / E_{0}^{k}}{f_{2}^{k} / f_{20}^{k},} \\
u_{B_{2}}\left(\delta_{2}\right)=\exp \left(-4\left(\delta_{2}-\delta_{2}^{*}\right)^{2}\right),
\end{gathered}
$$

where $\delta_{1}^{*}$ and $\delta_{2}^{*}$ are the optimal ratios, $u^{*}$ is the best coordination degree, $E_{0}^{k}$ and $E^{k}$ are the economic growth indicators for the current year and the planning year (such as per capita GDP, per capita net income, etc.) (yuan), $f_{20}^{k}$ and $f_{2}^{k}$ are the amount of important pollutants discharged in the current year and the planning year in sub-district $k$ (ton).

(5) Restrictions of variable non-negative

$$
x_{i j}^{k}, x_{c j}^{k} \geq 0
$$

\subsubsection{Solving and Optimizing Model}

The NSGA-II method (Non-dominated Sorting Genetic Algorithm-II) was used to solve the optimization model. The NSGA-II, first proposed by Deb et al. in 2002, is an improved version of the NSGA [40]. One of the most important propositions of the NSGA-II is that it proposes to modify the non-dominating sorting process to accelerate it [41]. The performance of NSGA-II approaches are carried out with respect to multi-objective performance measures [42,43] and the characteristic feature of NSGA-II is its fast non-dominated sorting procedure for ranking solutions in its 
selection [40,44]. The NSGA-II algorithm contains three main parts for selection of the new generation's members, including non-dominated sorting, density estimation, and a crowded comparison [45]. The specific processes include the following: (1) After randomly generating an initial population of $P_{0}$, non-dominated sorting was conducted with the population, where each individual was assigned a rank and then the binary tournament selection, crossover, and mutation were performed on the initial population so as to generate a new population, $Q_{0}$, assuming $t=0$. (2) The new group $R_{t}=P_{t} \cup Q_{t}$ was formed and non-dominated sorting was applied to $R_{t}$, thus obtaining the non-dominated front $F_{1}, F_{2}$, and so on. (3) Having sorted all the crowding distances, $F_{i}$, with the comparison operation $P_{n}$, the best $\mathrm{N}$ individuals were selected to generate population $P_{t+1}$. (4) The replication, crossover, and mutation were performed on the population $P_{t+1}$ to generate the population $Q_{t+1}$. (5) If the termination condition was satisfied, then the process would end; otherwise, assuming $t=t+1$, the process would return to Step (2). There have been several successful applications of the NSGA-II method in recent years and more information about the NSGA-II algorithm can be found in Zhang et al. [38,40,46-50].

According to the decomposition and coordination techniques of large system theory, the secondary hierarchical multi-objective optimization model was established. The model coordination method among decomposition-coordination techniques was used to pre-allocate the public water resources that associate with regions of restraint variables. This generated pre-allocated programs for five water resources partitions, thereby dividing the system into five independent sub-systems. The optimal integrated efficiency was achieved through repeated coordination of the allocated amount. The model optimization and the solution process are shown in Figure 3.

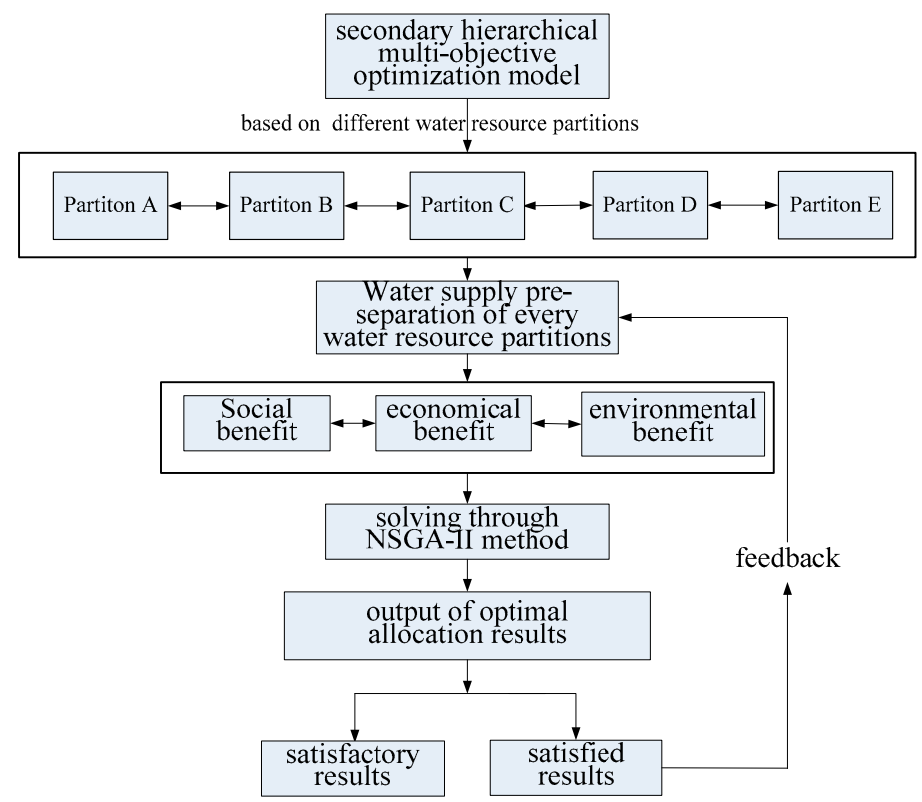

Figure 3. Model optimization and solution process (In the figure, Pastoral Energy Industry Partition, Farming-Pastoral Industrial Development Partition, Ecological Agriculture Preserved Partition, Sustainable Development for Petroleum and Coal Industry Partition and Preserved Partition for Ecological Agriculture and Sustainable Coal Industry Development Partition are abbreviated as A-E).

(1) Optimization of first-level sub-systems

The first-level sub-system was divided into $k$ sub-regions. Under the premise of fixed pre-allocated public resources given by the second level (coordination level), that is as follows.

$$
\sum_{k=1}^{k} D_{c}^{k} \leq W_{c} .
$$


Every sub-region was solved by NSGA-II. The optimized model for $k$ th sub-partition is as follows:

$$
\begin{gathered}
F_{k}\left(X^{k}\right)=\left\{f_{1}^{k}\left(X^{k}\right), f_{2}^{k}\left(X^{k}\right), f_{3}^{k}\left(X^{k}\right)\right\}, \\
\sum_{j=1}^{J(k)} x_{c j}^{k} \leq D_{c}^{k}(c=1,2, \ldots, M), \\
X_{c j}^{k} \leq Q^{c}(j=1,2, \ldots, J(k)), \\
\sum_{j=1}^{(k)} x_{c j}^{k} \leq W_{i}^{k}(i=1,2, \ldots, I(k)), \\
X_{i j}^{k} \leq Q_{i}^{k}(j=1,2, \ldots, J(k)), \\
\sum_{i=1}^{I(k)} X_{i j}^{k}+\sum_{c=1}^{M} X_{c j}^{k} \leq D_{j, \max }^{k}(j=1,2, \ldots, J(k)), \\
\sum_{i=1}^{I(k)} X_{i j}^{k}+\sum_{c=1}^{M} X_{c j}^{k} \geq D_{j, \min }^{k}(j=1,2, \ldots, J(k)), \\
X_{i j}^{k}, X_{c j}^{k} \geq 0 .
\end{gathered}
$$

The local optimal solution, $X^{k}\left(D_{c}^{k}\right)$, and the optimal value, $F_{k}\left(X^{k}, D_{c}^{k}\right)$, were obtained by NSGA-II, both being the functions of pre-allocated public resources $D_{c}^{k}$. The solutions were meaningful, but were not necessarily the optimal coordination solution in the overall region. Therefore, it was necessary to feed the obtained solutions $X^{k}\left(D_{c}^{k}\right)$ and target values $F_{k}\left(X^{k}, D_{c}^{k}\right)$ back to the second level for conducting system coordination (all the symbols in the formula were mentioned in Sections 3.4.1 and 3.4.2).

(2) System coordination on the second level

The goal of coordination on the second level was to obtain the optimal allocation of public resources in sub-regions, namely, to solve the following problem for optimal allocation:

$$
\begin{gathered}
F(X)=\max \sum_{k=1}^{k} W_{k} F_{k}\left(X^{k}\right), \\
\sum_{k=1}^{k} D_{c}^{k} \leq D_{c}(c=1,2, \ldots, M), \\
\mu=\sqrt{\mu_{B_{1}}\left(\sigma_{1}\right) \mu_{B_{2}}\left(\sigma_{2}\right)} \geq \mu^{*}, \\
D_{c}^{k} \geq 0(c=1,2, \ldots, M ; k=1,2, \ldots, K) .
\end{gathered}
$$

All symbols in the formula were mentioned in Sections 3.4.1 and 3.4.2.

(3) Planning and decision to obtain the optimal program for water allocation

In accordance with the coordination results on the second level, the first level results were coordinated again to obtain the optimal solution [46-50].

\subsection{Generalization and Partitions of the Water Resource System of the Basin}

The basin's water resource system mainly comprises various water sources (surface water, groundwater, channel water (even inter basin), etc.), operation and storage projects, water transportation systems, a drainage system, and water users. The decisions on the water resource allocation have to take into account the objectives and demands, such as reflecting the important features and rules 
of optimal water resource allocation according to the simulation model results, generalizing the other aspects of the system, analyzing the various entities involved in the water resources system, and determining the basic elements for system generalization. According to the basin's natural geographical features and socio-economic development, and with due consideration of the region's water quantity and quality characteristics, the basin was divided into 5 water resource partitions, i.e., Pastoral Energy Industry Partition, Farming-Pastoral Industrial Development Partition, Ecological Agriculture Preserved Partition, Sustainable Development for Petroleum and Coal Industry Partition and Preserved Partition for Ecological Agriculture and Sustainable Coal Industry Development Partition (abbreviated as A, B, C, D, and E in the article), as shown in Figure 1. Due to the different socio-economic development and leading industries of different water resource partitions, different water supply guarantee rates and policies were adopted.

\section{Results and Discussion}

\subsection{Expert Consultant Probability Results of Supply and Demand Water Program}

The expert probability is scored at different development speeds and statistical expert probability consultation results. A total of $80 \%$ of the statistical results are listed in Table 4 . The probability of rapid socio-economic development in 2020 was 0.6 (larger possible) and, in 2030, was 0.4 (lesser possibility).

Table 4. Social economic development speed expert recommendation probability statistics table in 2020 and 2030. Please check the column that you think is possible.

\begin{tabular}{|c|c|c|c|c|c|}
\hline Year & $\begin{array}{c}\text { Development } \\
\text { Speed }\end{array}$ & $\begin{array}{c}\text { Very Likely } \\
\text { Possible }\end{array}$ & $\begin{array}{c}\text { Larger } \\
\text { Possible }\end{array}$ & $\begin{array}{c}\text { Lesser } \\
\text { Possibility }\end{array}$ & $\begin{array}{l}\text { Impossible } \\
\text { Possibility }\end{array}$ \\
\hline \multirow{2}{*}{2020} & High & & $\sqrt{ }$ & & \\
\hline & Low & * & $*$ & * & * \\
\hline 2030 & $\begin{array}{l}\text { High } \\
\text { Low }\end{array}$ & $*$ & $*$ & $\begin{array}{l}\sqrt{ } \\
*\end{array}$ & * \\
\hline
\end{tabular}

Note: ${ }^{*}$ is mutually exclusive with the scoring results. High-speed development and low-speed development are antagonistic. If the low speed is very likely, the high speed is impossible. If the low speed is large, the high speed is a small possibility. Therefore, it is only necessary to score the high speed.

Table 5 showed the probability of expert recommendation of new-built water conservancy project in 2030 ( $80 \%$ of the statistical results) and, according to this, the recommended probability and the available water amount of the different programs in the following were obtained.

Table 5. Expert probability consultation results of water conservancy project construction plan in 2030. Very likely possible, expressed by a, is 0.8 , larger possible, expressed by b, is 0.6 , lesser possibility, expressed by c, is 0.4 , and impossible possibility, expressed by $\mathrm{d}$, is 0.2 .

\begin{tabular}{ccc}
\hline Water Project & Water Supply Amount & $\begin{array}{c}\text { Expert Recommendation } \\
\text { Probability }\end{array}$ \\
\hline San Li Qiao Reservoir & 2000 & $\mathrm{a}$ \\
Water quality renovation project in the upper reaches & 1724 & $\mathrm{a}$ \\
of Malian River & 350 & $\mathrm{a}$ \\
Er Jiangchuang Water Diversion Project & 17,000 & $\mathrm{~b}$ \\
Malian River Reservoir & 400 & $\mathrm{a}$ \\
Urban Qianchi Baihu Project & 2666 & $\mathrm{~b}$ \\
Urban Wastewater Treatment and Utilization Project & 3124 & $\mathrm{c}$ \\
& 1344 & $\mathrm{~b}$ \\
Rural Rainwater Harvesting and Utilization Project & 1152 & $\mathrm{c}$ \\
\hline
\end{tabular}

The socio-economic levels are classified into high and low rate development. According to the socio-economic development rate and the water conservancy construction rate, a total of 12 programs 
were developed, consisting of four for 2020 and eight for 2030. Based on the results of expert consultation probabilities, the final scores of different programs were calculated, as shown in Tables 6 and 7.

Table 6. Expert advice probability results table of different supply and demand programs in 2020.

\begin{tabular}{cccccccccc}
\hline \multirow{2}{*}{ Programs } & \multicolumn{2}{c}{$\mathbf{1}$} & \multicolumn{2}{c}{$\mathbf{2}$} & \multicolumn{3}{c}{$\mathbf{3}$} & \multicolumn{2}{c}{$\mathbf{4}$} \\
\cline { 2 - 9 } & DR & PS & DR & PS & DR & PS & DR & PS \\
\hline Socio-economic development & low & 0.400 & low & 0.400 & low & 0.600 & low & 0.600 \\
Water conservancy construction & high & 0.344 & high & 0.656 & high & 0.344 & high & 0.656 \\
Programs probability & \multicolumn{2}{c}{0.138} & \multicolumn{2}{c}{0.262} & \multicolumn{2}{c}{0.206} & 0.394 \\
\hline
\end{tabular}

Note: DR is development rate, PS is probability scoring.

Table 7. Expert advice probability results table of different supply and demand programs in 2030.

\begin{tabular}{|c|c|c|c|c|c|c|c|c|}
\hline \multirow{2}{*}{ Programs } & 1 & 2 & 3 & 4 & 5 & 6 & 7 & 8 \\
\hline & \multicolumn{2}{|c|}{ Low (2020) } & \multicolumn{2}{|c|}{ High (2020) } & \multicolumn{2}{|c|}{ Low (2020) } & \multicolumn{2}{|c|}{ High (2020) } \\
\hline development rate & $\begin{array}{c}\text { low } \\
(2030)\end{array}$ & $\begin{array}{l}\text { high } \\
(2030) \\
0160\end{array}$ & $\begin{array}{c}\text { low } \\
(2030)\end{array}$ & $\begin{array}{l}\text { high } \\
\text { (2030) }\end{array}$ & $\begin{array}{l}\text { low } \\
\text { (2030) }\end{array}$ & $\begin{array}{l}\text { high } \\
\text { (2030) }\end{array}$ & $\begin{array}{c}\text { low } \\
(2030) \\
0360\end{array}$ & $\begin{array}{l}\text { high } \\
\text { (2030) }\end{array}$ \\
\hline $\begin{array}{l}\text { water conservancy } \\
\text { construction }\end{array}$ & low & low & low & low & high & high & high & high \\
\hline probability possibility & 0.088 & 0.059 & 0.132 & 0.088 & 0.152 & 0.101 & 0.228 & 0.152 \\
\hline
\end{tabular}

According to Table 6, the most probable probability of occurrence in 2020 is program 4, high-speed development of socio-economics and low-speed development of water conservancy projects, and the comprehensive probability is 0.394 .

As shown in Table 7, the most probable probability of occurrence in 2030 is program 7, high-speed development of socio-economics in 2020 and low-speed development of socio-economics and high-speed development of water conservancy projects in 2030, and the comprehensive probability is 0.228 .

\subsection{Forecasts and Balance Analyses of Water Supply and Demand}

The indicator analysis in the model simulation forecasts can be used to forecast the water demand in the Malian River Basin. The model can fully consider the factors affecting water consumption in the future, determine the corresponding water indicator and water consumption quota based on the trends of the main factors, and calculate the water demand for each planning year, according to the scale and water consumption quota of the users. The scale of users is forecasted and determined through different planning years and different socio-economic development rates, while the water consumption quota is forecasted through socio-economic development, water saving level, and so on. The water demand of each partition can be classified into 5 categories (industry, agricultural, living, ecological, and new energy industrial). The supply and demand balance analysis was mainly based on the functions of different water resource partitions, water demand amount, the distribution of water supply projects, the amount of water that can be given, and, most importantly, the distribution weights (first of all, to ensure domestic water, followed by energy bases, industrial water, and finally agricultural and ecological water). The supply and demand balance analysis results of Program 7 are shown in Figures 4 and 5. 


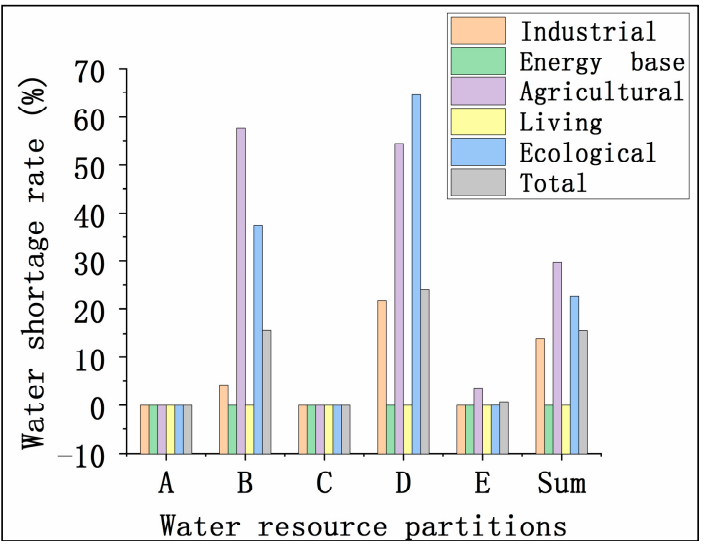

(a)

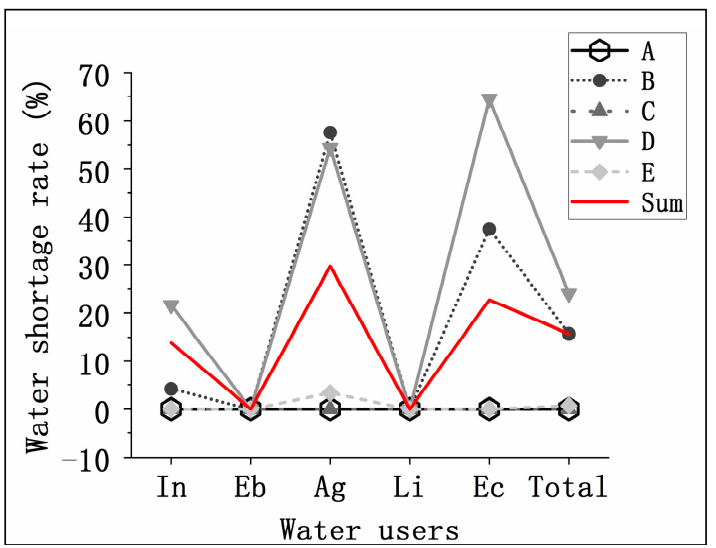

(b)

Figure 4. (a) Different water resource partitions, (b) different water users' water shortage rate analysis chart of weights distribution method (In the figure, Pastoral Energy Industry Partition, Farming-Pastoral Industrial Development Partition, Ecological Agriculture Preserved Partition, Sustainable Development for Petroleum and Coal Industry Partition, and Preserved Partition for Ecological Agriculture and Sustainable Coal Industry Development Partition were abbreviated as A-E; Industrial, Energy base, Agricultural, Living and Ecological were abbreviated as In, Eb, Ag, Li, and Ec).

As shown in Figure $4 \mathrm{a}$, under the development expectation of program 7, the higher water shortage rates were Partition D (24.04\%) and B (15.67\%), which increased the comprehensive water shortage rate $(15.62 \%)$ of the entire basin. The water shortage rate in Partition D was generally high and the top two high categories were ecological $(64.50 \%)$ and agricultural $(54.38 \%)$, while in Partition B they were agriculture $(57.54 \%)$ and ecology $(37.49 \%)$, followed by industry $(4.12 \%)$. Within the entire basin, agriculture $(29.70 \%)$ and ecology (22.74) had the most severe water shortage rates, followed by industry (13.84), and all living and energy bases guaranteed water use. The water shortage rate was 0 . Different industries and different water resources partitions had large fluctuations in water shortage rates (Figure 4b).

The amount of water available inside the basin was mainly determined by the centralized water supply project. As shown in Figure 5a, estimated by the development of the program 7 , the total water supply amount in the basin can reach $8.72 \times 10^{8} \mathrm{~m}^{3}$, of which the industrial proportion of the Partition $\mathrm{D}$ and $\mathrm{B}$ accounted for a large proportion, reaching 2.85 and $1.86 \times 10^{8} \mathrm{~m}^{3}$. Agriculture in Partition A $\left(0.50 \times 10^{8} \mathrm{~m}^{3}\right)$ was second. The water supply amount in the basin was decreased in accordance with industry $\left(5.40 \times 10^{8} \mathrm{~m}^{3}, 62 \%\right)$, agriculture $\left(1.64 \times 10^{8} \mathrm{~m}^{3}, 19 \%\right)$, life $\left(1.14 \times 10^{8} \mathrm{~m}^{3}, 13 \%\right)$, energy base $\left(0.36 \times 10^{8} \mathrm{~m}^{3}, 4 \%\right)$, and ecology $\left(0.17 \times 10^{8} \mathrm{~m}^{3}, 2 \%\right)$. The industrial and agricultural water supply amount reached $7.04 \times 10^{8} \mathrm{~m}^{3}$, accounting for more than $80 \%$ of the entire basin (Figure $5 \mathrm{~b}$ ). There are three main reasons that lead to these balance analysis results. First, different water users had different water distribution weights. Second, the water resource partitions had different functions and orientations. For instance, Partition B was the Farming-Pastoral Industrial Development Partition, therefore, industrial and agricultural development were dominant. Partition D was the Sustainable Development for Petroleum and Coal Industry Partition, where the development of a new energy base and industry was dominant. Third, because of the basin terrain and the location of the large water supply projects were different, water supply amount in different partitions varied.

With the results of program 7, whether the water supply amount in industrial or high water-consuming industries were too large? Whether the water consumption of energy base was too small? And whether the distribution of ecological water was too small? The above problems still needed to further verification and resolution. Was the water resource allocation reasonable enough and were the overall benefits were optimal for Program 7? Only by solving these problems can we further revise the function and positioning of different water resources partitions, determine the optimal 
water supply amount and methods, and provide guidance for the development and planning of the entire basin.

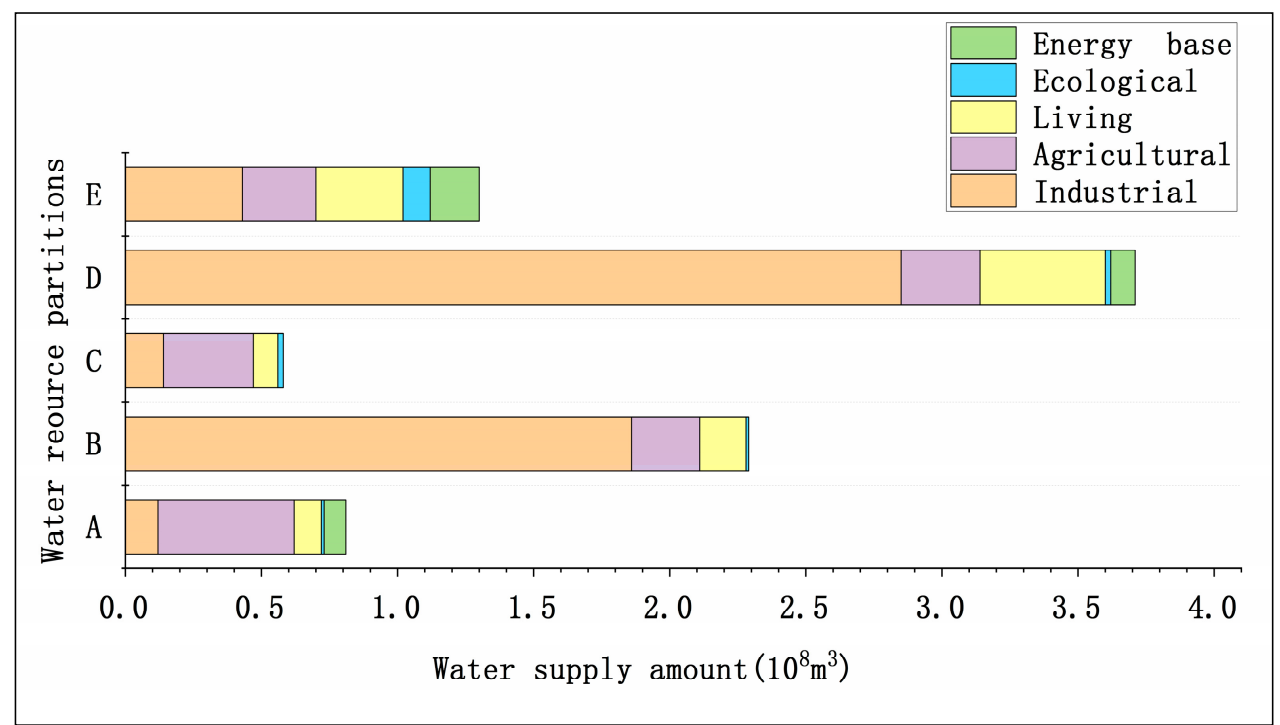

(a)

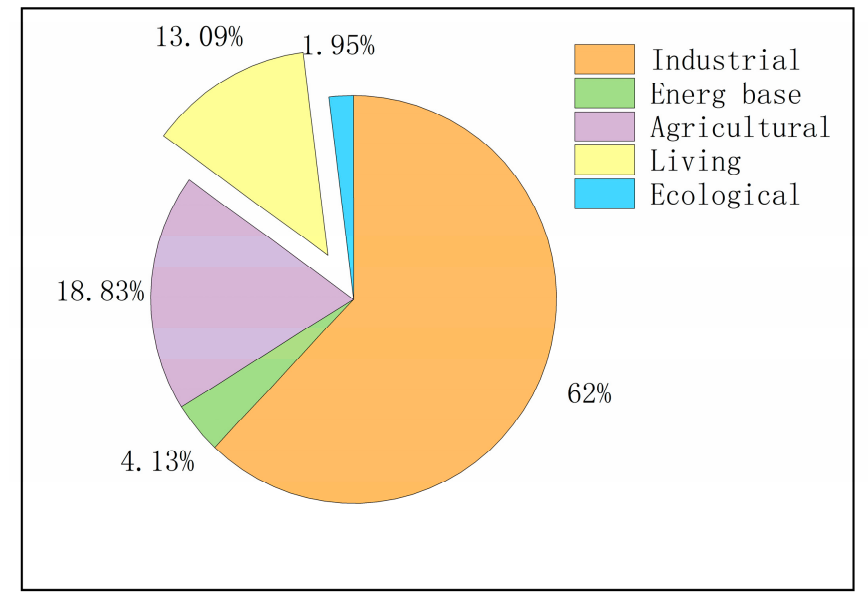

(b)

Figure 5. (a) Water supply analysis chart of weights distribution method (In the figure, Pastoral Energy Industry Partition, Farming-Pastoral Industrial Development Partition, Ecological Agriculture Preserved Partition, Sustainable Development for Petroleum and Coal Industry Partition and Preserved Partition for Ecological Agriculture, and Sustainable Coal Industry Development Partition were abbreviated as A-E). (b) Water supply analysis ratio chart of weights distribution method.

\subsection{Improved Decision Tree Analysis for Risk Decision}

The socio-economic development and water conservancy construction status in the 12 programs for 2020 and 2030 were drawn into the decision tree for risk decision analysis, as shown in Figures 6 and 7. The combination of socio-economic development and water conservancy construction for 2020 provided a total of four programs. Based on the supply-demand balance analysis results, the estimated water shortage for 2020 is $14.37 \%$. As such, Programs 2 and 3 were eliminated by the decision tree and the programs that were eligible for the optimal risk decision were Programs 1 and 3 . The combination of socio-economic development and water conservancy construction for 2030 generated eight programs. Based on the supply-demand balance analysis results, the estimated water shortage in 2030 is $21.68 \%$. As such, Programs 1, 4, and 8 were eliminated by the decision tree and the programs that were eligible for the optimal risk decision were Programs 5 and 7. 


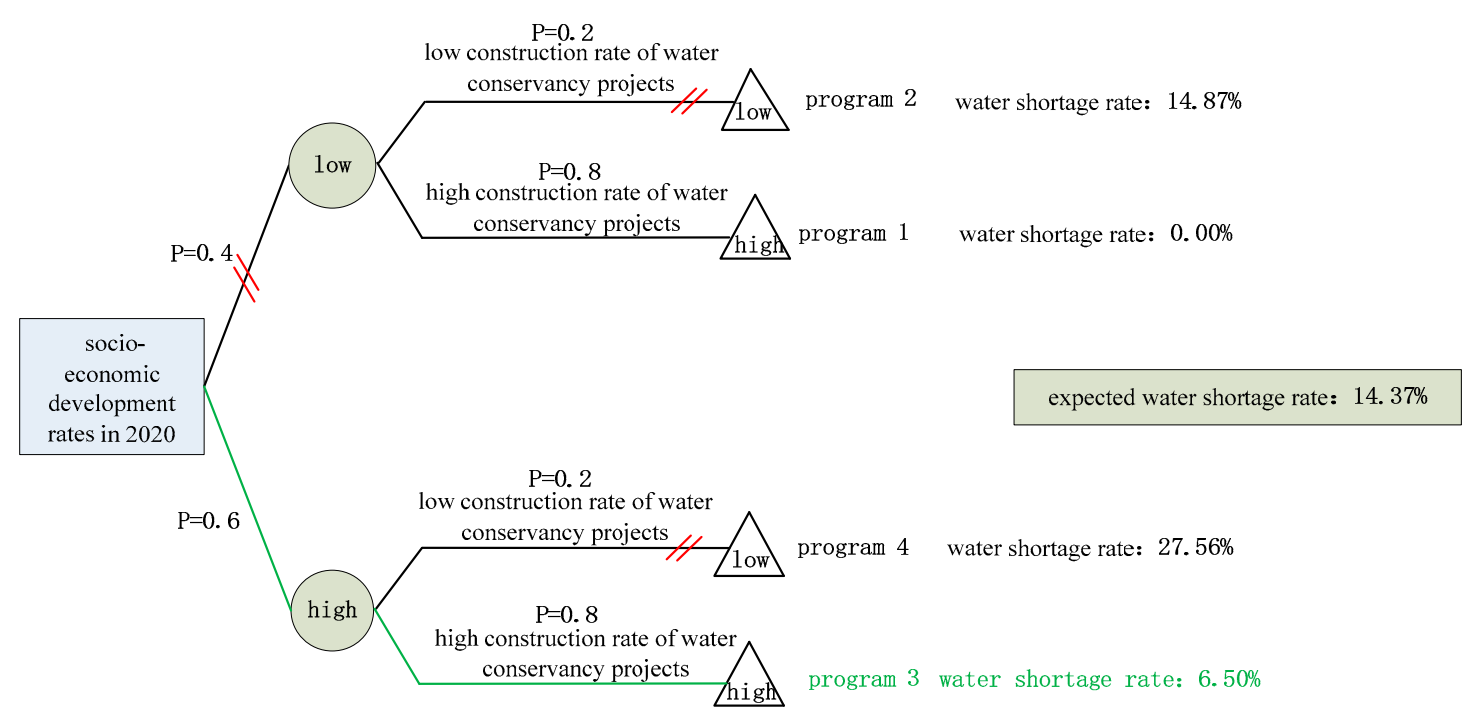

Figure 6. Decision tree method of socio-economic development and water conservancy projects construction for 2020 .

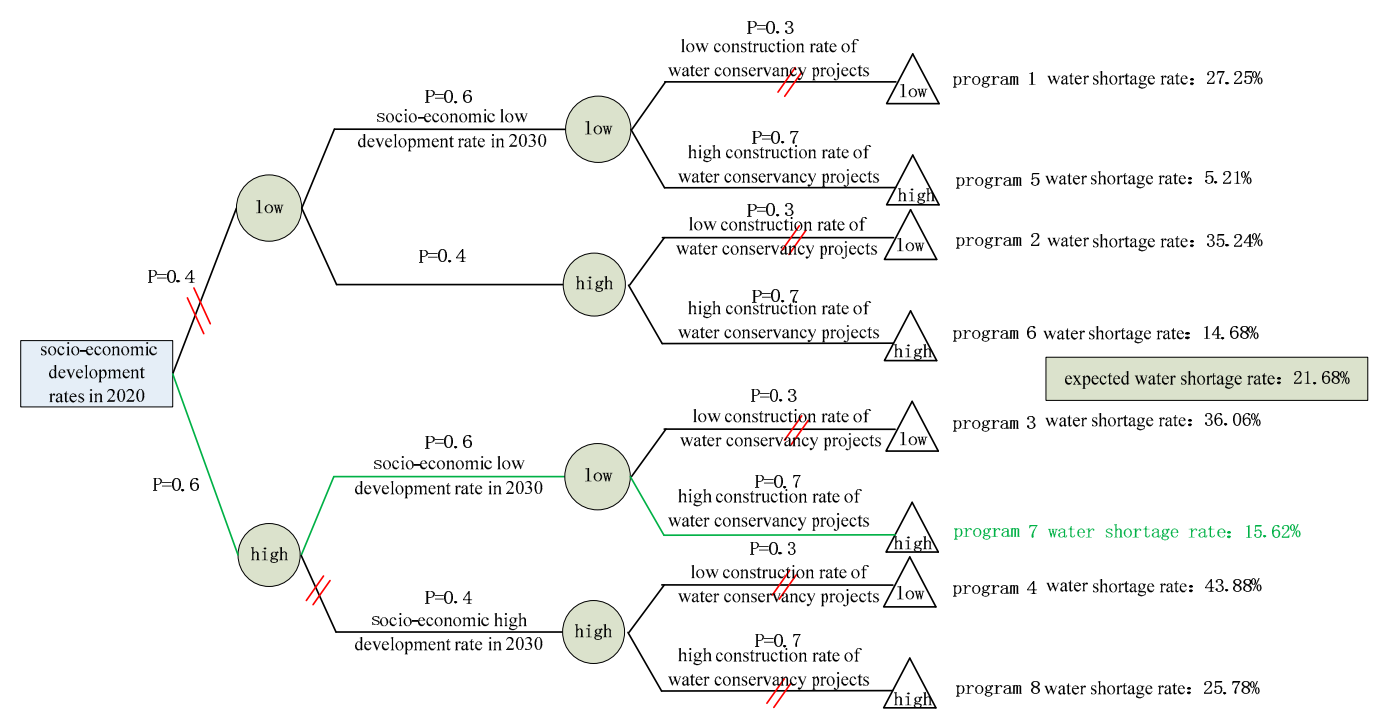

Figure 7. Decision tree method of socio-economic development and water conservancy projects construction for 2030.

Even after using the decision tree to carry out the risk analysis, there was still more than one potential optimal program for each planning year. In some cases, there were two or three. To select the optimal program, the expert advisory probabilistic method was introduced into the sensitivity analysis by a decision tree method. The experts' advisory results were used to screen the potential optimal programs, thereby obtaining the recommended programs for different planning years. According to the expert advisory results and the decision tree diagram, the probability of Program 3 for 2020 (high development rate) was 0.6, which was higher than the probability of Program 1 for 2020 (low development rate), which was 0.4. After the sensitivity analysis, Program 3 for 2020 (high socio-economic development rate and water conservancy construction rate) was eventually selected as the optimal decision program. Among the potential optimal programs for 2030, Programs 5 and 6 (low socio-economic development rate in 2020) had a probability of 0.4 , while the probability of Program 7 (high socio-economic development rate in 2020) was 0.6. Since the expert advisory probability of Program 7 was greater than that of Programs 5 and 6, Program 7 for 2030 (high 
socio-economic development rate in 2020 , low socio-economic development rate and high water conservancy construction rate in 2030) was selected as the recommend decision program.

In 2020 the recommended program (Program 3) was inconsistent with the large-probability program. The recommended program obviously had a low water shortage rate. The socio-economic situation of the high-probability scheme should be developed in accordance with the recommended program. Therefore, corresponding policies for promoting social development and water conservancy project construction should be formulated to promote development, following the direction of the recommended program. After changing the social economic development and water resource policy, in 2030, the high probability program is consistent with the recommended program, indicating that the corresponding policies have changed positively, which makes the recommendation program more likely to occur and water resources allocation and policy support are moving towards the recommended program. The formulation of policies determines the speed of social and economic development and the construction speed of water conservancy projects and, thus, determines the supply and demand amount for water.

The purpose of decision tree training is to produce a decision tree with a strong generalization ability and a strong ability to deal with unsuccessful examples. In the later stages of training, the decision tree algorithm can be written into a program using machine learning methods and selecting samples in semi-arid areas to train decision trees. Finally, the decision tree model of semi-arid areas is formed to improve the accuracy of the model and to distinguish different programs quickly, efficiently, and accurately, simultaneously simplifying the discriminating process and reducing the workload. However, the problem of rational allocation of the available water and benefit maximization among water users requires the establishment of the large systematic and multi-objective model to solve.

\subsection{Large Systematic and Multi-Objective Model}

The optimal allocation of water resources for different users is the basis of integrated management of water resources. By developing the multi-objective model for optimal allocation, the society, economy, and environment benefits can be optimal. Based on the present situation analyses of water supply and demand, the water supply and demand of the planning year can be forecasted. The large-scale and multi-objective model can then be employed to develop the model for optimal water resource allocation. The model generates five pre-sorting programs and five independent subsystems for water resource divisions and different water users, coordinates the allocation according to the objective function and constraints, and, finally, produces the optimal optimization results which have the system comprehensive benefits. The NSGA-II method was selected to generate a solution of the decision tree method recommendation program for 2030. Finally, the results were analyzed and compared. The following values were the parameters of the optimal model: Numbers of generation: 200, number of decision variables: 3 , population number: 500 , number of objective functions: 3 , number of restrictions: 5, coefficient parameter: 15 .

\subsubsection{Determining the Model's Parameters}

(1) Weight coefficients of partitions

The weight coefficient of partition $W_{k}$ represents the significance of partition $k$ for the entire economic zone. The weight coefficient of each water resource partition was calculated through the binary comparison method. The weight coefficients were as follows. The Pastoral Energy Industry Partition was 0.16; the Farming-Pastoral Industrial Development Partition was 0.16; the Ecological Agriculture Preserved Partition was 0.17; the Sustainable Development for Petroleum and Coal Industry was 0.26; and the Preserved Partition for Ecological Agriculture and Sustainable Coal Industry Development was 0.25 .

(2) Water supply sequence coefficients and fair coefficients of water consumption

(a) Water supply sequence coefficient 
The water supply sequence coefficient, $\alpha_{i}^{k}$, represents the priority degree of water source $i$ in partition $k$, as compared to the other sources of water supply. The priority degree of each water source is converted into a coefficient in the interval $[0,1]$. The water supply sequence coefficients are determined by the formula $\alpha_{i}^{k}=\frac{1+n_{\max }^{k}-n_{i}^{k}}{\sum_{j=1}^{J}\left[1+n_{\max }^{k}-n_{j}^{k}\right]}$. The water supply sequence coefficients were the following: A value of 0.28 for store water, 0.24 for pumping water, 0.19 for channel water, 0.14 for shallow groundwater, 0.10 for deep groundwater, and 0.05 for other water sources.

(b) Fair coefficient of water consumption

The user's fair coefficient, $\beta_{j}^{k}$, refers to the priority degree in obtaining water by a user in partition $k$, as compared to the priority degree enjoyed by other users. The formula for calculating $\beta_{j}^{k}$ is similar to that used to calculate $\alpha_{i}^{k}$. The fair coefficients were as follows: A value of 0.20 for industry, 0.27 for energy base, 0.13 for agriculture, 0.33 for life, and 0.07 for ecology.

(3) Efficiency coefficient of water consumption and cost coefficient

(a) The efficiency coefficient of water consumption

The efficiency coefficient of water consumption is a measure of economic benefit enjoyed by a user for one unit of the water supply. Based on the combination of data of statistical yearbooks and planning, the efficiency coefficients were: A value of 333 for industry, 400 for energy base, 250 for agriculture, 420 for life, and 200 for ecology.

(b) The cost coefficient of water supply

The cost coefficients of water supply for different water resources partitions were: A value of 4.70 for the Pastoral Energy Industry Partition, 2.00 for the Farming-Pastoral Industrial Development Partition, 2.35 for the Preserved Partition for Ecological Agriculture, 1.50 for the Sustainable Development for Petroleum and Coal Industry Partition, and 0.50 for The Preserved Area for Ecological Agriculture and Sustainable Coal Industry Development Partition.

(4) The emission coefficient of pollutants

Referring to the statistic data of urban sewage discharge in the China Environment Statistical Yearbook (2017), the Qingyang Statistical Yearbook (2017), the Qingyang Environmental Quality Report (2017), and other relevant information, the emission coefficients of pollutants in the basin from different water users in different planning years were determined. The emission coefficients of pollutants for 2030 are: A value 1.19 for industry, 1.22 for energy base, 0.94 for agriculture, 10.76 for life, and 0.05 for ecology.

\subsubsection{Large-System Multi-Objective Optimal Model Results}

With the aid of MATLAB2016, the NSGA-II was used to generate a solution from the model. The recommended risk decision program (Program 7) for 2030 was used as an example of optimization. The results of running the optimization model running showed that the total water supply in the Malian River Basin is $8.69 \times 10^{8} \mathrm{~m}^{3}$ and the comprehensive water shortage rate is $15.90 \%$.

As shown in Figure $8 \mathrm{a}$, through model optimization, the highest water shortage rates were still in Partition D $(24.05 \%)$ and Partition B (16.31\%), resulting in a higher water shortage rate $(15.90 \%)$ in the entire Malian River Basin. The comprehensive water shortage rate in Partition D (24.05\%) was the highest among the 5 partitions, with agriculture $(41.17 \%)$ and industry $(24.61 \%)$ being more significant, followed by living $(4.37 \%)$ and ecological $(0.97 \%)$ water shortage. The comprehensive water shortage rate in Partition B (16.31\%) ranked second, caused by the high water shortage rate of agriculture $(21.18 \%)$ and industry $(16.40 \%)$. Ecology $(1.25 \%)$ also contributed. Living and energy bases were not short of water at high water supply guarantee rates. The comprehensive water shortage rate of Partitions A $(0.74 \%), \mathrm{C}(0.81 \%)$, and E $(0.78 \%)$ were all below $1 \%$ and the three partitions were not short of water, which indicated that the model results were good. Within the entire basin, industry $(19.48 \%)$ and agriculture (17.05\%) had the most severe water shortages, followed by living $(1.77 \%)$. Energy bases $(0.02 \%)$ and ecological $(0.99 \%)$ basically all guaranteed water and the water shortage rates were both below $1 \%$ (Figure 8 b). 


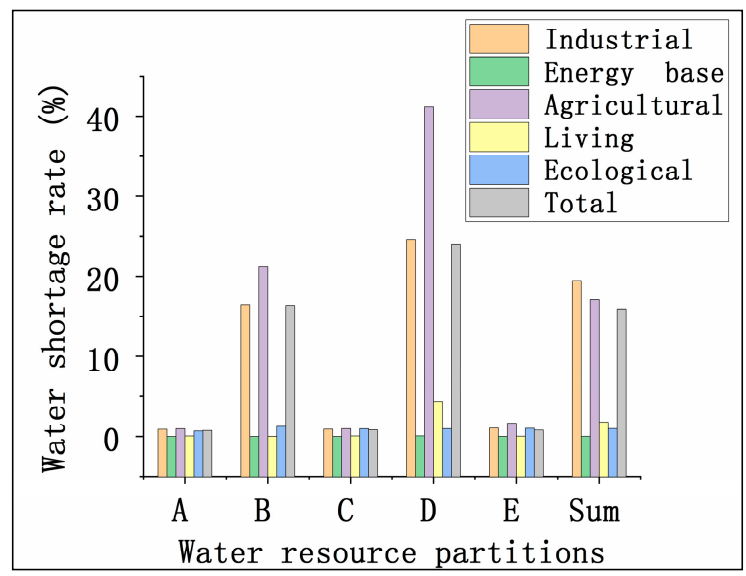

(a)

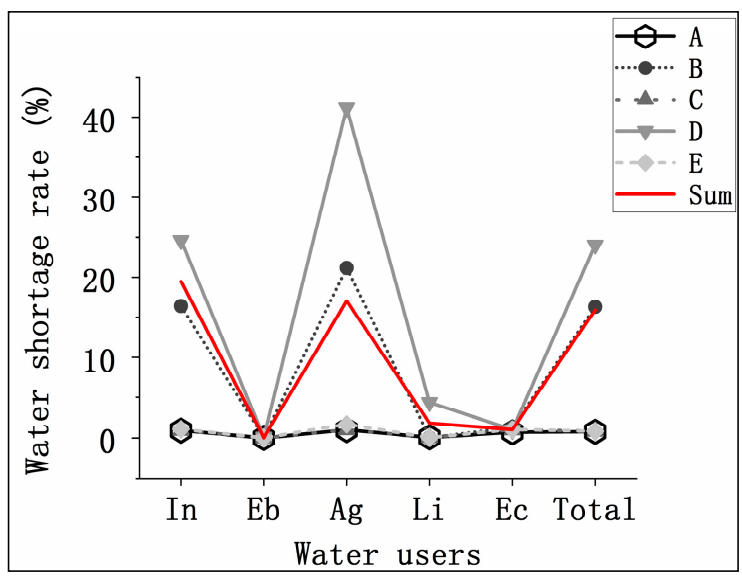

(b)

Figure 8. (a) Different water resource partitions, (b) different water users. Water shortage rate analysis chart of model method (In the figure, Pastoral Energy Industry Partition, Farming-Pastoral Industrial Development Partition, Ecological Agriculture Preserved Partition, Sustainable Development for Petroleum and Coal Industry Partition, and Preserved Partition for Ecological Agriculture and Sustainable Coal Industry Development Partition were abbreviated as A-E; Industrial, Energy base, Agricultural, Living and Ecological were abbreviated as In, Eb, Ag, Li and Ec).

The amount of water that can be supplied was determined by a large-scale centralized water conservancy project and the water demand was constant under certain social and economic development conditions. Therefore, unless a new water supply was added through a new water conservancy project, the water shortage rate was difficult to reduce. The model had such a running result based on the optimality of society, economy, and environment benefit, and water saving potential was found. The agricultural water shortage rate in Partition D reached $41.17 \%$, which is an urgent problem to be solved. So, it is necessary to adjust the agricultural structure and improve water use efficiency. Partition B also had the same problem. Only by solving the problem of water shortages for industry and agriculture in Partition D and B can we solve the water crisis in the basin and enable the limited water resources to fully support the high-speed social and economic development of the basin.

The model results can help us to find water-saving potential, start water conservation from different water users, and improve water use efficiency. Examples include, choosing efficient water-saving industries, improving recycling efficiencies, and shutting down high water consumption industries. In Agriculture, the following measures can be very effective, such as water-saving irrigation, raise the standard of irrigation quota, perform high-efficiency irrigation in the critical water demand period of crops and plant low water consumption crops. And make more use of unconventional water resources also effective, such as brackish water and rainwater. Domestic water can be improved from the use of 
water-saving appliances. Ecological water can be substantially resolved from the use of unconventional water resources (collected rainwater resources).

As shown in Figure 9a, the result of the optimization model was that the water supply amount within the entire basin was $8.69 \times 10^{8} \mathrm{~m}^{3}$. Partition $\mathrm{D}\left(3.72 \times 10^{8} \mathrm{~m}^{3}\right)$ and $\mathrm{B}\left(2.28 \times 10^{8} \mathrm{~m}^{3}\right)$ were ranked first and second, and Partition E $\left(1.30 \times 10^{8} \mathrm{~m}^{3}\right)$ was ranked third. Partition A $\left(0.82 \times 10^{8} \mathrm{~m}^{3}\right)$ and C $\left(0.58 \times 10^{8} \mathrm{~m}^{3}\right)$ had less water supply amounts due to less water demand. In Partition D, the industrial $\left(2.74 \times 10^{8} \mathrm{~m}^{3}\right)$ water supply amount was larger, accounting for $73.66 \%$ of the entire Partition $\mathrm{D}, 31.53 \%$ of the entire Malian River Basin, and was followed by life $\left(0.44 \times 10^{8} \mathrm{~m}^{3}\right)$, agriculture $\left(0.33 \times 10^{8} \mathrm{~m}^{3}\right)$ third, while the other two items were both less than $0.10 \times 10^{8} \mathrm{~m}^{3}$. The main reason was that the function of Partition D was sustainable development for the petroleum and coal industries and industry and life are dominant, so the water supply amount for them were large and, thus, the agricultural water was greatly reduced. Partition B was the Farming-Pastoral Industrial Development Partition, therefore, the industry $\left(16.40 \times 10^{8} \mathrm{~m}^{3}\right)$ and agricultural $\left(0.47 \times 10^{8} \mathrm{~m}^{3}\right)$ water supply amounts were ranked in the top two, while agricultural had a high water shortage rate of $21.18 \%$. It is necessary to implement policies to improve agricultural structure and to promote water-saving agriculture. The water supply amount in Partition E was $1.30 \times 10^{8} \mathrm{~m}^{3}$, ranking third out of the five partitions, of which industry $\left(0.42 \times 10^{8} \mathrm{~m}^{3}\right)$, living $\left(0.32 \times 10^{8} \mathrm{~m}^{3}\right)$, and agriculture $\left(0.28 \times 10^{8} \mathrm{~m}^{3}\right)$ ranked in the top three and accounted for $78.46 \%$ of the entire Partition E. Such results were related to the function of Partition E, ecological agriculture and sustainable coal industry development.

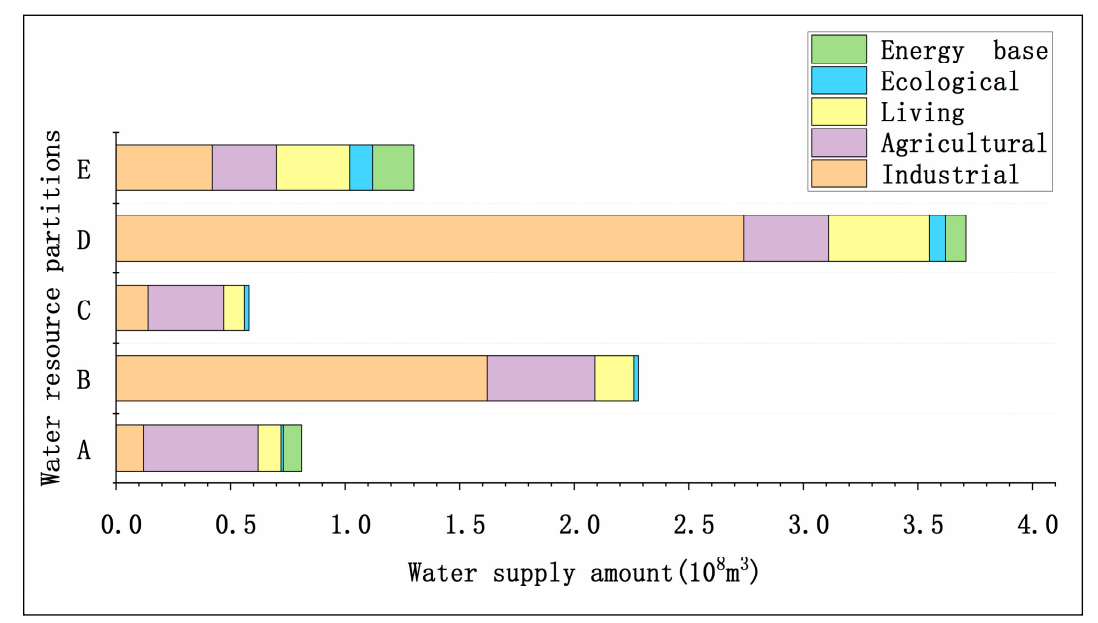

(a)

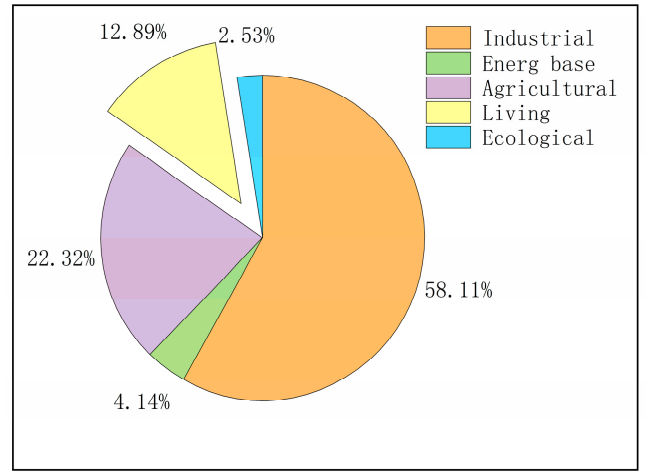

(b)

Figure 9. (a) Water supply analysis chart of model method (In the figure, Pastoral Energy Industry Partition, Farming-Pastoral Industrial Development Partition, Ecological Agriculture Preserved Partition, Sustainable Development for Petroleum and Coal Industry Partition and Preserved Partition for Ecological Agriculture and Sustainable Coal Industry Development Partition were abbreviated as A-E). (b) Water supply analysis ratio chart of model method. 
The results of the optimization model are shown in Figure $9 \mathrm{~b}$. The water supply amount in the basin was decreasing in accordance with industry $\left(5.05 \times 10^{8} \mathrm{~m}^{3}, 58 \%\right)$, agriculture $\left(1.94 \times 10^{8} \mathrm{~m}^{3}\right.$, $22 \%)$, life $\left(1.12 \times 10^{8} \mathrm{~m}^{3}, 13 \%\right)$, energy base $\left(0.36 \times 10^{8} \mathrm{~m}^{3}, 4 \%\right)$, and ecology $\left(0.22 \times 10^{8} \mathrm{~m}^{3}, 3 \%\right)$. The industrial and agricultural water supply amount reached $6.99 \times 10^{8} \mathrm{~m}^{3}$, accounting for $80 \%$ of the entire basin. The industrial water shortage rate was $19.48 \%$, agricultural was $17.05 \%$, living was $1.77 \%$ and the energy base and ecological were all below $1 \%$, indicating that the model method ran better results.

\subsection{Comparative Analysis of Optimization Results of NSGA-II}

Taking the decision tree method proposed program (Program 7) as an example, the results of the model method and weights method were compared and analyzed, as shown in Figure 10.

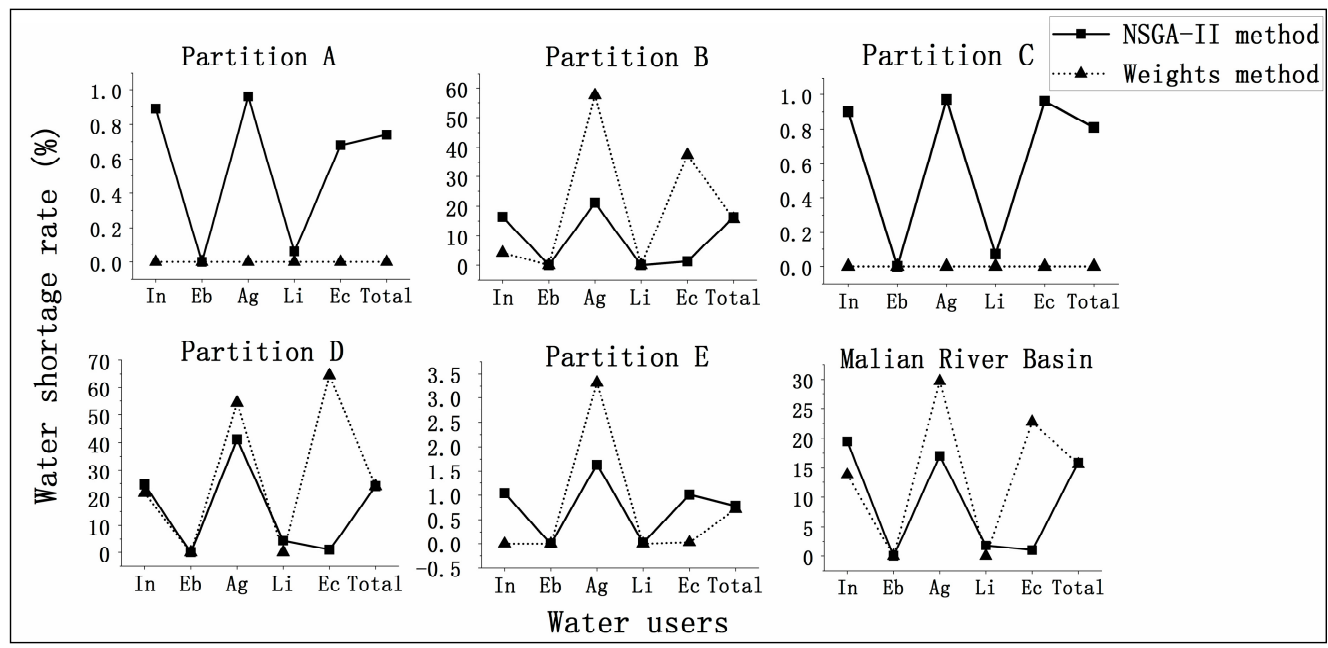

Figure 10. Comparative analysis chart of the model method and weights distribution method (In the figure, Pastoral Energy Industry Partition, Farming-Pastoral Industrial Development Partition, Ecological Agriculture Preserved Partition, Sustainable Development for Petroleum and Coal Industry Partition and Preserved Partition for Ecological Agriculture and Sustainable Coal Industry Development Partition were abbreviated as A-E; Industrial, Energy base, Agricultural, Living and Ecological were abbreviated as $\mathbf{I n}, \mathbf{E b}, \mathbf{A g}, \mathbf{L i}$, and $\mathbf{E c})$.

The comprehensive water supply amount in the basin and the water shortage rates results are shown in Table 8 . The total water shortage rate of the model method increased by $0.28 \%$ compared to the weights method, while the total water supply amount decreased by $0.03 \times 10^{8} \mathrm{~m}^{3}$. The water supply amount and the water shortage rate of the whole basin were similar, but there was a large difference between different water users (Figure 10 and Table 8).

Table 8. Optimization model method result table in 2030.

\begin{tabular}{|c|c|c|c|c|c|c|c|}
\hline Water Resource Partitions & $\begin{array}{c}\text { Item } \\
\left(10^{8} \times \mathrm{m}^{3} / \%\right)\end{array}$ & Industrial & $\begin{array}{c}\text { Energy } \\
\text { Base }\end{array}$ & Agricultural & Living & $\begin{array}{l}\text { Ecological } \\
\text { Water }\end{array}$ & Total \\
\hline \multirow{2}{*}{ Pastoral Energy Industry Partition } & water supply & 0.12 & 0.08 & 0.50 & 0.10 & 0.01 & 0.82 \\
\hline & shortage rate & 0.89 & 0.00 & 0.96 & 0.06 & 0.68 & 0.74 \\
\hline \multirow{2}{*}{ Farming-Pastoral Industrial Development Partition } & water supply & 1.62 & 0.00 & 0.47 & 0.17 & 0.02 & 2.28 \\
\hline & shortage rate & 16.40 & 0.00 & 21.18 & 0.01 & 1.25 & 16.31 \\
\hline \multirow{2}{*}{ Ecological Agriculture Preserved Partition } & water supply & 0.14 & 0.00 & 0.33 & 0.09 & 0.02 & 0.58 \\
\hline & shortage rate & 0.90 & 0.00 & 0.97 & 0.07 & 0.96 & 0.81 \\
\hline \multirow{2}{*}{$\begin{array}{l}\text { Sustainable Development for Petroleum and Coal } \\
\text { Industry Partition }\end{array}$} & water supply & 2.74 & 0.09 & 0.37 & 0.44 & 0.07 & 3.72 \\
\hline & shortage rate & 24.61 & 0.08 & 41.17 & 4.37 & 0.97 & 24.05 \\
\hline \multirow{2}{*}{$\begin{array}{l}\text { Preserved Partition for Ecological Agriculture and } \\
\text { Sustainable Coal Industry Development Partition }\end{array}$} & water supply & 0.42 & 0.18 & 0.28 & 0.32 & 0.10 & 1.30 \\
\hline & shortage rate & 1.04 & 0.01 & 1.63 & 0.03 & 1.01 & 0.78 \\
\hline \multirow{2}{*}{ Malian River Basin } & water supply & 5.05 & 0.36 & 1.94 & 1.12 & 0.22 & 8.69 \\
\hline & shortage rate & 19.48 & 0.02 & 17.05 & 1.77 & 0.99 & 15.90 \\
\hline
\end{tabular}




\subsubsection{Different Water Users}

(1) Industry

In water users for industry, the model method had a water supply of $5.05 \times 10^{8} \mathrm{~m}^{3}$, a water shortage rate of $19.48 \%$, and the weights method $\left(5.40 \times 10^{8} \mathrm{~m}^{3}, 13.84 \%\right)$. The decline in the water supply amount led to an increase in the water shortage rate in the model method. The problem of the increased water shortage rate can be solved by phasing out high water consuming industries and recycling water resources efficiently (Figure 10 and Table 8).

(2) Agriculture

In water users for agriculture, the model method $\left(1.94 \times 10^{8} \mathrm{~m}^{3}, 17.05 \%\right)$ and the weights method $\left(1.64 \times 10^{8} \mathrm{~m}^{3}, 29.70 \%\right)$ indicated that the water supply amount increased by $0.30 \times 10^{8} \mathrm{~m}^{3}$ and the water shortage rate decreased by $12.65 \%$. The model method effectively improved the agricultural water shortage problem. However, compared with other water users, the water shortage rate of $17.05 \%$ was still too high. So, it is necessary to improve the level of agricultural production, promote water-saving agriculture, and use unconventional water resources to solve the problem of the high water shortage rate (Figure 10 and Table 8).

(3) Ecology

In water users for ecology, the model method $\left(0.22 \times 10^{8} \mathrm{~m}^{3}, 0.99 \%\right)$ and the weights method $\left(0.17 \times 10^{8} \mathrm{~m}^{3}, 22.74 \%\right)$ indicated that the water supply amount increased by $0.05 \times 10^{8} \mathrm{~m}^{3}$ and the water shortage rate decreased by $21.75 \%$. In the face of China's efforts to increase ecological construction, it is of great practical significance to increase water resource support for ecological construction. In addition, the remaining water shortage rate problem can be effectively collected by using rainwater resources to increase water supply and reducing conventional water resource use by switching to non-conventional water resources (Figure 10 and Table 8).

(4) Energy Base

In water users for the energy base, the model method $\left(0.36 \times 10^{8} \mathrm{~m}^{3}, 0.02 \%\right)$ and the weights method $\left(0.36 \times 10^{8} \mathrm{~m}^{3}, 0.00 \%\right)$ indicated that the water supply amount reduced by $0.0001 \times 10^{8} \mathrm{~m}^{3}$ and the water shortage rate was only $0.02 \%$. This can be solved by the optimization of the water use structure and through water saving in the energy base industry (Figure 10 and Table 8).

(5) Living

In water users for living, the model method $\left(1.12 \times 10^{8} \mathrm{~m}^{3}, 1.77 \%\right)$ and the weights method $\left(1.14 \times 10^{8} \mathrm{~m}^{3}, 0.00 \%\right)$ indicated that the water supply amount reduced by $0.02 \times 10^{8} \mathrm{~m}^{3}$ and the water shortage rate increased by $1.77 \%$. The rising water shortage rate can be solved by using water-saving appliances and secondary water in daily life (Figure 10 and Table 8.).

The water supply amount of different water users (industrial, energy base, agricultural, living, and ecological) was determined by the objective function and restrictions of the optimization model; however, the water shortage rates were still high in the case of constant total water supply amount. In addition to the above-mentioned water saving and efficient use of water measures, the hierarchical sequence of reused water can be used to reduce the water shortage rate. The waste water can be reused in living, small-scale agricultural, and ecological water use through centralized collection and processing. In new energy base industries with high water quality and water consumption, so the wastewater from new energy industry can be reused in general industry, or through processing, reused in new energy industries, general industries, agricultural and ecological sectors [24].

\subsubsection{Different Water Resource Partitions}

(1) Partition A

For different water resource partitions, the functions of Partition A were positioned as a pastoral energy industry. The model method was based on the optimal social, economic, and ecological benefits, reducing the energy base and ecological water supply amount by $1.00 \times 10^{8} \mathrm{~m}^{3}$ and $2.00 \times 10^{8} \mathrm{~m}^{3}$ respectively, resulting in a comprehensive water shortage rate of $0.74 \%$ in Partition A. The problem of the rising water shortage rate can be solved by saving water inside the energy base and using 
rainwater resources efficiently. The water supply amount of the weights method was in line with the water demand amount and the water shortage rate was 0 . The weights method did not consider the overall benefits. Of course, the differences in water supply amounts between the two methods were not significant (Figure 10 and Table 8).

(2) Partition B

The functions of Partition B were positioned for farming-pastoral industrial development. The water shortage rate of the model method was $16.31 \%$, which was $0.64 \%$ higher than that of the weights method, which was caused by the reduction of the water supply amount by $0.02 \times 10^{8} \mathrm{~m}^{3}$. The water shortage rate of agriculture in Partition B decreased significantly from 57.54\% to $21.18 \%$. The ecological decreased from $37.49 \%$ to $1.25 \%$, which was in line with the requirements of improving ecological development and solved the problem of water shortage in agriculture. The industrial water shortage rate increased from $4.12 \%$ to $16.40 \%$, which was due to the reduction of the industrial water supply. The increased water shortage rate can be solved by eliminating high-water consumption industries and optimizing the industrial structure in Partition B (Figure 10 and Table 8).

(3) Partition C

The functions of Partition $C$ were positioned as preserved ecological agriculture and the main purpose was to protect the ecology and for the stable development of agriculture. The model method reduced the amount of water supply to all water users, and resulted in a small increase in the water shortage rate, but no more than $1.00 \%$. The problem of risen water shortages rate can be solved through the use of unconventional water resources, efficient collection and use of rainwater resources and brackish water resources (Figure 10 and Table 8).

(4) Partition D

The functions of Partition D were positioned as for the sustainable development of the petroleum and coal industry. According to the goal of optimal overall benefit, the model method increased the ecological water supply and reduced the water shortage rate from $64.50 \%$ to $0.97 \%$, which greatly reduced the ecological water shortage rate and met the policy requirements for increasing ecological construction, under the premise of ensuring the sustainable development of the petroleum and coal industry. At the same time, the model method increased the amount of water supplied in agriculture and the water shortage rate reduced from $54.38 \%$ to $41.17 \%$. The remaining water users remained basically unchanged. However, agriculture still had a high water shortage rate, which can be reduced by implementing water-saving agriculture, reducing crop water consumption, and efficient water-saving irrigation (Figure 10 and Table 8).

(5) Partition E

The functions of Partition E were positioned as for ecological agriculture and sustainable development of coal industry. The comprehensive water shortage rate of the model method increased by $0.06 \%$ and the agricultural water shortage rate was reduced from $3.32 \%$ to $1.63 \%$, which was in line with the development of the partition. According to the aim of maximizing the overall benefits, the industrial water supply amount reduced by $0.01 \times 10^{8} \mathrm{~m}^{3}$ and the water shortage rate increased by $1.04 \%$. The rise in the water shortage rate can be reduced by adjusting the industrial structure and increasing the recycling rate of water resources. The ecological water supply amount increased by $0.067 \times 10^{8} \mathrm{~m}^{3}$ and the water shortage rate also increased by $0.98 \%$, which indicated that the ecological water demand of the partition had increased. The rising water shortage rate did not exceed $1 \%$. It can be supplemented by the collected unconventional water resources without increasing the amount of water supply (Figure 10 and Table 8).

Obviously, the optimization model method had better distribution results for every water user in different water resources partitions, the overall benefits were optimal, and the social, economic, and ecological benefits were maximized. Through the model results, the water saving potential was found, the water supply amount was reduced, and the water shortage rate was reduced. The results can provide a reference for both the planning of water resources and the formulation of corresponding efficient use of water policies. Most important, the results can provide a strong guarantee for the rapid 
development of both the regional economy and the energy industry. For other basins in semi-arid areas, the decision tree method and optimization model are also suitable for discovering water saving potentials and formulating water policies through setting model parameters based on different benefit requirements.

\section{Conclusions}

An analytical framework for assessing socioeconomic development, the rational allocation of water resources, and guiding policy development was proposed in this study. The Malian River Basin was divided into five water partitions and was given different functions for the optimal allocation of water resources. An indicator analysis method was used to forecast the water supply and demand and to conduct a preliminary water balance analysis. The expert advisory probabilistic method was introduced to score the 12 programs in 2020 and 2030. A decision tree method was used in the risk analysis and was improved by introducing the expert advisory probabilistic method into the sensitivity analysis to reduce the cognitive and motivational bias of expert advisors. Then, the recommended programs were obtained, which were Program 3 (high socioeconomic development rate and water conservancy construction rate) in 2020 and Program 7 (high socioeconomic development rate in 2020, low socio-economic development rate and high water conservancy construction rate in 2030) in 2030, and the probabilities of the recommended scheme were 0.206 and 0.228 , respectively, according to the current level of social and economic development level without policy intervention. In 2020, the recommended program was inconsistent with the large-probability program, so the socioeconomic situation of the high-probability program should be changed in accordance with the recommended program. The policies for promoting social development and water conservancy project construction were formulated to promote development following the direction of the recommended program. A large-system multi-objective model was introduced to solve the problem of rational allocation of the available water resources and maximizing the benefits for the water users. The NSGA-II method was used to generate a solution from the model to seek water allocation programs when social, economic, and environmental benefits were maximized. The results in 2030 were as follows:

The water supply amount within the entire basin was $8.69 \times 10^{8} \mathrm{~m}^{3}$ and the comprehensive water shortage rate was $15.90 \%$. For different partitions, Partition D $\left(3.72 \times 10^{8} \mathrm{~m}^{3}, 24.05 \%\right)$ and B $\left(2.28 \times 10^{8} \mathrm{~m}^{3}, 16.31 \%\right)$ were ranked first and second, and Partition E $\left(1.30 \times 10^{8} \mathrm{~m}^{3}, 0.78 \%\right)$ was ranked third. Partition A $\left(0.82 \times 10^{8} \mathrm{~m}^{3}, 0.74 \%\right)$ and $\mathrm{C}\left(0.58 \times 10^{8} \mathrm{~m}^{3}, 0.81 \%\right)$ had a lesser water supply amount due to the lesser water demand. For different users, the water supply amount and shortage rate in the basin decreased in accordance with industry $\left(5.05 \times 10^{8} \mathrm{~m}^{3}, 58 \%\right)$, agriculture $\left(1.94 \times 10^{8} \mathrm{~m}^{3}\right.$, $22 \%)$, life $\left(1.12 \times 10^{8} \mathrm{~m}^{3}, 13 \%\right)$, energy base $\left(0.36 \times 10^{8} \mathrm{~m}^{3}, 4 \%\right)$, and ecology $\left(0.22 \times 10^{8} \mathrm{~m}^{3}, 3 \%\right)$. The industrial and agricultural water supply amount reached $6.99 \times 10^{8} \mathrm{~m}^{3}$, accounting for $80 \%$ of the entire basin. The industrial water shortage rate was $19.48 \%$, agricultural was $17.05 \%$, living was $1.77 \%$, and the energy base and ecological shortage rates were all below $1 \%$, indicating these two users were not short of water. The available water supply amount was determined by a water conservancy project. Unless a new water supply was added through a new water conservancy project, the water shortage rate is difficult to reduce. The optimization model method had better distribution results than the weights method, so that the overall benefits are optimal and social, economic, and ecological benefits were maximized without a new water supply. Through the model results, the water saving potential was found to improve water use efficiency and the related policies are proposed as follows: Choosing efficient water-saving industries, improving recycling efficiencies, and shutting down high water consumption industries. In Agriculture, the following measures can be very effective, such as water-saving irrigation, raise the standard of irrigation quota, perform high-efficiency irrigation in the critical water demand period of crops and plant low water consumption crops. And make more use of unconventional water resources also effective, such as brackish water and rainwater Domestic water can be improved by the use of water-saving appliances. Ecological water can be substantially resolved by the use of unconventional water resources. This framework and these methods can further provide 
a reference for both the planning of water resources and the formulation of regulatory policies and will greatly alleviate water crises in semi-arid areas.

Author Contributions: Conceptualization, Y.G., X.Z. (Xinmin Zhang) and X.Z. (Xiaoyou Zhang), Data acquisition, J.T. and Y.G.; Funding acquisition, Y.G. and X.Z. (Xinmin Zhang); Formal analysis, D.L. and M.Y.; Investigation, Y.G., M.Y. and X.Z. (Xinmin Zhang); Methodology, X.Z. (Xinmin Zhang) and X.Z. (Xiaoyou Zhang); Visualization, D.L. and Y.G.; Writing-original draft, Y.G.

Funding: This work was financially supported by the National Key Research and Development Plan (2017YFC0504704), the Technology Promotion Projects of Water Conservation Research in Gansu ([2013]293, [2014]223, [2015]55), the Young Creative Talents Support Program in Longyuan ([2014]93), Gansu Provincial Key Research and Development Plan (18YF1NA031), and the Water Resources Foundation Support Project of Gansu Provincial Water Resources Department ([2017]293).

Acknowledgments: The authors would like to thank Gansu Provincial Meteorological Bureau, Water Affairs Bureau of Qingyang City and Statistics Affairs Bureau of Qingyang City for providing climatic and water resources data.

Conflicts of Interest: The authors declare no conflict of interest.

\section{References}

1. Ma, J.; Pan, F.; He, J.; Chen, L.; Fu, S.; Jia, B. Petroleum pollution and evolution of water quality in the Malian River Basin of the Longdong Loess Plateau, Northwestern China. Environ. Earth Sci. 2012, 66, 1769-1782. [CrossRef]

2. Lin, M.; Chen, L.; Ma, Y. Research on stream flow series fractal dimension analysis and its relationship with soil erosion. In Proceedings of the 2013 IEEE International Geoscience and Remote Sensing Symposium-IGARSS, Melbourne, VIC, Australia, 21-26 July 2013; pp. 1821-1823.

3. Huang, Y.F.; Chen, X.; Huang, G.H.; Chen, B.; Zeng, G.M.; Li, J.B.; Xia, J. GIS-based distributed model for simulating runoff and sediment load in the Malian River Basin. Hydrobiologia 2003, 494, 127-134. [CrossRef]

4. Wang, Y.; Cheng, X.; Zhang, M.; Qi, X. Hydrochemical characteristics and formation mechanisms of Malian River in Yellow River basin during dry season. Environ. Chem. 2018, 37, 164-172. (In Chinese)

5. Zhang, Y.; Zhang, D.; Liu, Y. Precipitation variation in Malianhe River Basin of the Loess Plateau in recent 50 years. Sci. Soil Water Conserv. 2016, 14, 44-52. (In Chinese)

6. Zhou, F.; Zha, X.; Huang, C.; Wang, X.; Sang, J. Study on Holocene Paleoflood in Malian River Basin. Prog. Geogr. 2011, 30, 1081-1087.

7. Zhang, Y.; Rui, F.; Xiong, S. Fuzzy set theory and reservoir optimization. J. Huazhong Univ. Sci. Technol. 1983, $5,25-34$.

8. Bekri, E.; Disse, M.; Yannopoulos, P. Optimizing water allocation under uncertain system conditions for water and agriculture future scenarios in Alfeios River Basin (Greece)—Part B: Fuzzy-boundary intervals combined with multi-stage stochastic programming model. Water 2015, 7, 6427-6466. [CrossRef]

9. Chhuon, K.; Herrera, E.; Nadaoka, K. Application of integrated hydrologic and river basin management modeling for the optimal development of a multi-purpose reservoir project. Water Resour. Manag. 2016, 30, 3143-3157. [CrossRef]

10. Terêncio, D.P.S.; Fernandes, L.F.S.; Cortes, R.M.V.; Pacheco, F.A.L. Improved framework model to allocate optimal rainwater harvesting sites in small watersheds for agro-forestry uses. J. Hydrol. 2017, 550, 318-330. [CrossRef]

11. Kosolapova, N.A.; Matveeva, L.G.; Nikitaeva, A.Y.; Molapisi, L. Modeling resource basis for social and economic development strategies: Water resource case. J. Hydrol. 2017, 553, 438-446. [CrossRef]

12. Birigazzi, L.; Gamarra, J.G.P.; Gregoire, T.G. Unbiased emission factor estimators for large-area forest inventories: Domain assessment techniques. Environ. Ecol. Stat. 2018, 25, 199-219. [CrossRef]

13. Turpie, J.; Joubert, A. Estimating potential impacts of a change in river quality on the tourism value of Kruger National Park: An application of travel cost, contingent and conjoint valuation methods. Water SA 2001, 27, 387-398. [CrossRef]

14. Ren, C.; Li, Z.; Zhang, H. Integrated multi-objective stochastic fuzzy programming and AHP method for agricultural water and land optimization allocation under multiple uncertainties. J. Clean. Prod. 2019, 210, 12-24. [CrossRef] 
15. Ahmadi, A.; Karamouz, M.; Moridi, A.; Han, D. Integrated planning of land use and water allocation on a watershed scale considering social and water quality issues. J. Water Resour. Plan. Manag. 2012, 138, 671-681. [CrossRef]

16. Zoltay, V.I.; Vogel, R.M.; Kirshen, P.H.; Westphal, K.S. Integrated Watershed Management Modeling: Generic Optimization Model Applied to the Ipswich River Basin. J. Water Resour. Plan. Manag. 2010, 27, 566-575. [CrossRef]

17. Maiolo, M.; Mendino, G.; Pantusa, D.; Senatore, A. Optimization of drinking water distribution systems in relation to the effects of climate change. Water 2017, 9, 803. [CrossRef]

18. Maiolo, M.; Pantusa, D.; Carini, M.; Capano, G.; Chiaravalloti, F.; Procopio, A. A new vulnerability measure for water distribution network. Water 2018, 10, 1005. [CrossRef]

19. Maiolo, M.; Pantusa, D. A proposal for multiple reuse of urban wastewater. J. Water Reuse Desalin. 2018, 8, 468-478. [CrossRef]

20. Chen, D.; Leon, A.S.; Gibson, N.L.; Hosseini, P. Dimension reduction of decision variables for multireservoir operation: A spectral optimization model. AGU Water Resour. Res. 2015, 52, 36-51. [CrossRef]

21. Lerma, N.; Paredes-Arquiola, J.; Andreu, J.; Solera, A.; Sechi, G.M. Assessment of evolutionary algorithms for optimal operating rules design in real Water Resource Systems. Environ. Model. Softw. 2015, 69, 425-436. [CrossRef]

22. Maiolo, M.; Martirano, G.; Morrone, P.; Pantusa, D. Assessment criteria for a sustainable management of the water resources. Water Pract. Technol. 2006, 1. [CrossRef]

23. Maiolo, M.; Pantusa, D. Combined reuse of wastewater and desalination for the management of water systems in conditions of scarcity. Water Ecol. 2017, 4, 116-126.

24. Maiolo, M.; Daniela, P. Sustainable Water Management Index, SWaM Index. Cogent Eng. 2019, 6, 1603817. [CrossRef]

25. Lei, X.; Zhang, J.; Wang, H.; Wang, M.; Khu, S.; Li, Z.; Tan, Q. Deriving mixed reservoir operating rules for flood control based on weighted non-dominated sorting genetic algorithm II. J. Hydrol. 2018, 564, 967-983. [CrossRef]

26. Esogbue, A.O.; Liu, B. Reservoir operations optimization via fuzzy criterion decision processes. Fuzzy Optim. Decis. Mak. 2006, 5, 289-305. [CrossRef]

27. Qin, H. Multi-Objeetive Optimal Operation and Multi-Attribute Risk Decision Making of Caseaded Hydropower Stations. Ph.D. Thesis, Huazhong University of Science and Technology, Wuhan, China, 2011; pp. 13-16. (In Chinese)

28. Li, K. Study on Methods of Multi-Objective Decision Making and Risk Analysis in Reservoir Operation; North China Electric Power University: Beijing, China, 2013; pp. 21-25. (In Chinese)

29. Zhang, J.; Wang, X.; Liu, P.; Lei, X.; Li, Z.; Gong, W.; Duan, Q.; Wang, H. Assessing the weighted multi-objective adaptive surrogate model optimization to derive large-scale reservoir operating rules with sensitivity analysis. J. Hydrol. 2017, 544, 613-627. [CrossRef]

30. Li, Q.; Ouyang, S. Research on multi-objective joint optimal flood control model for cascade reservoirs in river basin system. Nat. Hazards 2015, 77, 2097-2115. [CrossRef]

31. Yazdi, J. Decomposition based multi objective evolutionary algorithms for design of large-scale water distribution networks. Water Resour. Manag. 2016, 30, 2749-2766. [CrossRef]

32. Werth, S.; Güntner, A. Calibration analysis for water storage variability of the global hydrological model WGHM. Hydrol. Earth Syst. Sci. 2010, 14, 59-78. [CrossRef]

33. Hamarat, C.; Kwakkel, J.H.; Pruyt, E.; Loonen, E.T. An exploratory approach for adaptive policymaking by using multi-objective robust optimization. Simul. Model. Pract. Theory 2014, 46, 25-39. [CrossRef]

34. Wang, M.; Yu, S. Combining scenario-based multi-objective optimized decision-making with a spatial division strategy: A case study of Yongding River, Beijing, China. Environ. Earth Sci. 2015, 74, 6639-6646. [CrossRef]

35. Han, Y.; Ruan, B.; Wang, D. Multi-objective risk decision-making model for regional water resources shortage. J. Hydraul. Eng. 2008, 6, 667-668.

36. Baltar, A.M.; Fontane, D.G. Use of multiobjective particle swarm optimization in water resources management. J. Water Resour. Plan. Manag. 2008, 134, 257-265. [CrossRef]

37. Chen, L.; McPhee, J.; Yeh, W.W.G. A diversified multiobjective GA for optimizing reservoir rule curves. Adv. Water Resour. 2007, 30, 1082-1093. [CrossRef] 
38. Atiquzzaman, M.; Liong, S.-Y.; Yu, X. Alternative decision making in water distribution network with NSGA-II. J. Water Resour. Plan. Manag. 2006, 132, 122-126. [CrossRef]

39. Zhou, Z. Machine Learning; Tsinghua University Press: Beijing, China, 2016; pp. 73-83.

40. Deb, K.; Pratap, A.; Agarwal, S.; Meyarivan, T.A. A fast and elitist multiobjective genetic algorithm: NSGA-II. IEEE Trans. Evol. Comput. 2002, 6, 182-197. [CrossRef]

41. Hamdani, T.M.; Won, J.M.; Alimi, A.M.; Karray, F. Multi-objective Feature Selection with NSGA II. In International Conference on Adaptive and Natural Computing Algorithms 2007; Springer: Berlin/Heidelberg, Germany, 2007; Volume 4431, pp. 240-247.

42. Coello, C.A.C.; Pulido, G.T.; Lechuga, M.S. Handling multiple objectives with particle swarm optimization. IEEE Trans. Evol. Comput. 2004, 8, 256-279. [CrossRef]

43. Jeyadevi, S.; Baskar, S.; Babulal, C.K.; Iruthayarajan, M.W. Solving multiobjective optimal reactive power dispatch using modified NSGA-II. Electr. Power Energy Syst. 2011, 33, 219-228. [CrossRef]

44. Li, H.; Zhang, Q. Multiobjective Optimization Problems with Complicated Pareto Sets, MOEA/D and NSGA-II. IEEE Trans. Evol. Comput. 2009, 13, 284-286. [CrossRef]

45. Monsef, H.; Naghashzadegan, M.; Jamali, A.; Farmani, R. Comparison of evolutionary multi objective optimization algorithms in optimum design of water distribution network. Ain Shams Eng. J. 2019, 10, 103-111. [CrossRef]

46. Zhou, Y.; Liu, J.; Zhang, Y.; Gan, X. A multi-objective evolutionary algorithm for multi-period dynamic emergency resource scheduling problems. Transp. Res. Part E Logist. Transp. 2017, 99, 77-95. [CrossRef]

47. Zhang, S.; Guo, H.; Zhu, K.; Yu, S.; Li, J. Multistage assignment optimization for emergency rescue teams in the disaster chain. Knowl. Based Syst. 2017, 137, 123-137. [CrossRef]

48. Ghasemi, P.; Khalili-Damghani, K.; Hafezolkotob, A.; Raissi, S. Uncertain multi-objective multi-commodity multi-period multi-vehicle location-allocation model for earthquake evacuation planning. Appl. Math. Comput. 2019, 350, 105-132. [CrossRef]

49. Bekele, E.; Nicklow, J. Multi-objective optimal control model for watershed management using SWAT and NSGA-II. World Environ. Water Resour. Congr. 2007, 1-10. [CrossRef]

50. Ding, S.; Dong, Z.; Wang, Z.; Li, Q. MOP of feeding reservoir group optimal operation based on SPEA. Adv. Water Sci. 2008, 195, 679-684. 